\title{
A reflexão da luz nos periódicos de Ensino de Física: evidenciando tendências e carências de pesquisa a partir de uma revisão bibliográfica ${ }^{+*}$
}

\section{Jair Lúcio Prados Ribeiro ${ }^{1}$}

Doutorando do Programa de Pós-Graduação em Educação em Ciências

Universidade de Brasília

Brasília - DF

Maria Helena da Silva Carneiro ${ }^{2}$

Faculdade de Educação

Universidade de Brasília

Brasília - DF

\section{Resumo}

O artigo apresenta uma revisão bibliográfica acerca da reflexão luminosa. Foram revisados 152 artigos sobre o tema, publicados em revistas acadêmicas brasileiras e internacionais voltadas de forma específica para o ensino de física, entre 1995 e 2015. O diálogo entre os artigos foi estabelecido a partir de dez categorias de classificação dos textos, de acordo com o seu subtema específico: princípios da reflexão, refletância, velocidade da luz, reflexão difusa, imagens reais e virtuais, espelhos planos, espelhos curvos, associações de espelhos, polarização e espelhos relativísticos. A revisão evidenciou grande concentração de esforços de pesquisa em aplicações de espelhos curvos e planos. Por outro lado, temas como refletância, velocidade da luz, espelhos relativísticos e a relação entre os fenômenos da reflexão e da polarização mostraram carência de trabalhos. A revisão mostrou que esses quatro subtemas não são usuais nas publicações de autores brasileiros, demonstrando possibilidades de pesquisas futuras. $O$ uso de materiais cotidianos em atividades experimentais também foi evidenciado, principalmente em artigos voltados para o

\footnotetext{
${ }^{+}$Light reflection in Physics Teaching journals: highlighting research trends and needs from a literature review

* Recebido: fevereiro de 2016. Aceito: abril de 2016.

${ }^{1}$ E-mail: jairlucio@gmail.com

2 E-mail: mhsilcar@unb.br
} 
tratamento da óptica no ensino médio, fato que contribui para a continuidade de pesquisas sobre o tema. Ressalta-se ainda que a celebração do Ano Internacional da Luz (2015) não parece ter alavancado de forma substancial as publicações sobre o tema.

Palavras-chave: Reflexão; Óptica; Ensino de Óptica; Ensino de Física.

\begin{abstract}
The article presents a literature review on light reflection, in which 152 articles on the subject were reviewed. The texts were published between 1995 and 2015 in Brazilian and International Physics academic education journals. The dialogue between the articles was established from ten categories of text classification, according to their specific sub-theme: principles of reflection, reflectance, speed of light, diffuse reflection, real and virtual images, flat mirrors, curved mirrors, mirror associations, polarization and relativistic mirrors. The review showed a great concentration of research efforts in applications of flat and curved mirrors. On the other hand, there is shortage of research in other themes such as reflectance, speed of light, relativistic mirrors and the relationship between reflection and polarization phenomena. The review showed that Brazilian authors do not usually publish articles about these four sub-themes, which demonstrates possibilities for future research. The use of everyday materials in experimental activities was also evidenced, especially on articles about high school topics, a fact that contributes for the continuity of researches on the topic. It is noteworthy that the celebration of the International Year of Light (2015) did not substantially boost publications on the subject.
\end{abstract}

Keywords: Reflection; Optics; Optics Teaching; Physics Teaching.

\title{
I. Introdução
}

O texto presente se propõe a apresentar uma ampla revisão bibliográfica sobre o tema da reflexão da luz em periódicos de ensino de física. A prática de organizar publicações anteriores em artigos científicos de revisão bibliográfica vem de longa data, pois tais trabalhos são publicados desde o século XIX. Figueiredo (1990) defende que esse formato de artigo tem duas vertentes principais: a revisão descritiva das contribuições da literatura sobre um determinado tema e a revisão analítica, centrada em um problema científico particular. Acreditamos que nosso trabalho esteja mais correlacionado à primeira vertente, mas com a presença de alguns elementos analíticos, principalmente no tocante à contextualização dos temas revisados. 
Em um esforço de revisão anterior (RIBEIRO; VERDEAUX, 2012a), no qual categorizamos os artigos dedicados à experimentação em óptica, publicados em periódicos nacionais de ensino de física, já defendíamos a necessidade da prática sistemática de revisões sobre subtemas da área de ensino de ciência, dado o crescimento das pesquisas nessa área nos últimos vinte anos. Assim procedemos por acreditar que os primeiros passos de um pesquisador, em qualquer campo de investigação, devem envolver a leitura de revisões recentes acerca do tema, a fim de que o mesmo possa tomar contato com o estado da arte da área, minimizando o risco de produção de pesquisas repetitivas.

A especificação dos subtemas é notória em revisões recentes, devido à facilidade com que os trabalhos podem ser selecionados. Antes do advento das redes de computadores, um pesquisador poderia contar apenas com os periódicos impressos ou microfilmados disponíveis na biblioteca de sua universidade, ou deveria empreender grandes esforços para ter acesso a um maior escopo de fontes, tais como empréstimos das obras físicas entre universidades ou mesmo uma "viagem de pesquisa" a uma instituição que contivesse uma maior riqueza de fontes. Em áreas específicas, revisões também eram conduzidas a partir dos content reviews dessas disciplinas, os quais correspondiam a publicações impressas que catalogavam resumos de periódicos de uma área em um intervalo de tempo.

A partir dos anos 1990, entretanto, a popularização da internet e a migração das revistas acadêmicas para a rede mundial de computadores levou a uma ampliação dessas bases de dados. Apesar da facilidade de acesso a uma multiplicidade de fontes bibliográficas, a dificuldade financeira se mantém, pois a consulta aos artigos completos nem sempre é gratuita, principalmente nos periódicos estrangeiros.

Esse maior acesso às publicações acadêmicas por parte dos pesquisadores permitiu que as revisões pudessem se tornar mais específicas e abrangentes. Ostermann e Moreira (2000), por exemplo, conduziram uma extensa revisão sobre a área de ensino da física moderna e contemporânea no ensino médio, incluindo a consulta a diversas fontes, tais como livros didáticos, periódicos, dissertações, teses e projetos voltados ao tema, que seria inviabilizada ou ao menos enfraquecida sem o poderio trazido pela revolução digital ${ }^{3}$. O tema da revisão desenvolvida por esses autores não é generalista, ao contrário, é bastante específico, razão pela qual os autores incluíram fontes não tradicionais em sua pesquisa, como sítios visitados de forma aleatória na internet.

A revisão desenvolvida por Ferreira e Queiroz (2012), acerca de textos de divulgação científica no ensino de ciências, também exemplifica as especificidades das revisões de literatura atuais: vinte e cinco periódicos nacionais voltados ao ensino de ciências foram incluídos na base de pesquisa, além das atas de todas as edições dos ENPEC (Encontro Nacional de Pesquisa em Ensino de Ciências), contendo os trabalhos completos publicados nesses eventos. Quase noventa textos compõem tal revisão, a qual não inclui publicações em periódicos ou

\footnotetext{
${ }^{3}$ Frisa-se que o artigo de Ostermann e Moreira (op. cit., 2000) não pode ser considerado uma revisão bibliográfica tradicional, por não incluir apenas artigos acadêmicos, correspondendo a um trabalho mais amplo.
} 
eventos internacionais.

Pelo exposto, já imaginávamos como extenso o número de trabalhos a serem incluídos nesse artigo, no qual é proposta a revisão de publicações acerca do tema da reflexão luminosa em periódicos nacionais e estrangeiros voltados ao ensino de física. Nossa intenção inicial era uma revisão ainda mais abrangente dos temas da óptica, incluindo a refração e seus fenômenos associados, mas percebemos que a tarefa seria hercúlea, razão pela qual preferimos manter a presente revisão focada em um tema mais específico, reservando os demais fenômenos para trabalhos posteriores.

Optamos pela presença de artigos presentes em periódicos nacionais e internacionais, publicados em diversos países, a fim de trazer maior abrangência para o trabalho. Essa escolha foi feita por acreditarmos que revisões baseadas apenas em publicações nacionais correm o risco de não expor o real estado da arte da área, principalmente se o tema revisado for interdisciplinar ou se correlacionar com áreas de tecnologia de ponta. Acreditamos que a reflexão da luz, conteúdo sobre o qual essa revisão se desenvolve, apresenta tais características.

\section{Metodologia da revisão}

Dada a efervescência na pesquisa na área de ensino de física nas últimas décadas e a crescente disponibilidade de periódicos em formato eletrônico, recortes dessa ampla literatura acadêmica disponível se fizeram obrigatórios. Para os fins dessa revisão, optou-se por priorizar artigos dedicados ao tema da reflexão presentes em revistas acadêmicas que sejam voltadas de forma predominante para o ensino de física. Assim, não foram consultados periódicos voltados para o ensino de ciências em geral. A Fig. 1 exibe o número de artigos presentes nessa revisão, organizados por ano de publicação ${ }^{4}$.

A presente revisão foi conduzida para artigos publicados entre 1995 e 2015, com vistas a fornecer um panorama detalhado do estado da arte das pesquisas sobre o tema. Ressalta-se que artigos dedicados à reflexão interna total não foram incluídos, pois esse fenômeno tem relação direta com a refração da luz e não com a reflexão per se. Estudos sobre radiômetros também não estão presentes, pois nos artigos consultados, o funcionamento desses aparelhos se vincula às leis da termodinâmica e não à reflexão óptica. Já artigos sobre holografia só foram incluídos caso apresentassem correlação direta com o fenômeno da reflexão, e não a mera citação do espelho em seus aparatos. Interferômetros também utilizam espelhos em sua constituição, mas não encontramos nenhum artigo que se dedicasse à reflexão luminosa com tais aparelhos, razão pela qual tais trabalhos também estão ausentes.

\footnotetext{
${ }^{4}$ Até fevereiro de 2016, momento que o manuscrito foi submetido à análise dos árbitros do CBEF, os periódicos Gazeta de Física, Latin-American Journal of Physics Education e Reflets de la Physique ainda não haviam disponibilizado em seus portais eletrônicos suas edições de dezembro de 2015.
} 


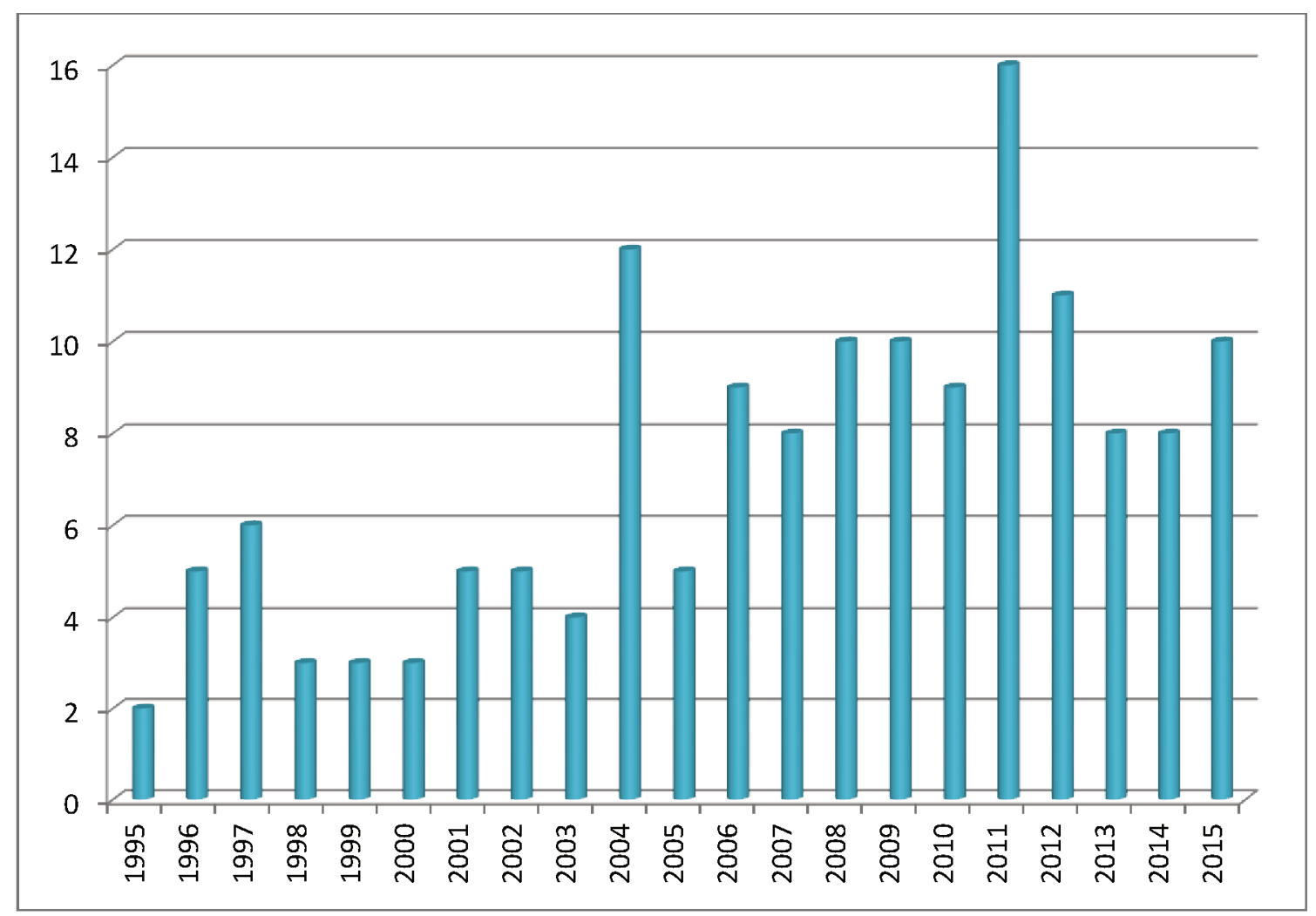

Fig. 1 - Número de publicações sobre a reflexão em periódicos de ensino de física entre 1995 e 2015.

O perceptível crescimento no número de publicações sobre a reflexão em periódicos de ensino de física (Fig. 1) a partir de meados da primeira década do século XXI não se revela, a nosso ver, uma exclusividade desse tema. No início da década citada, Bueno (2001) já considerava como "vertiginoso" o crescimento na produção de pesquisas na área educacional, tanto no aumento de trabalhos publicados quanto no ritmo dessa produção, pois os estudos publicados estavam sendo produzidos em intervalos de tempo menores. Mesmo se as pesquisas ficarem restritas apenas à área de ensino de ciências, tal crescimento também se verifica, como aponta Delicoizov (2004). Ademais, alguns dos periódicos consultados só começaram a ser editados nos anos mais recentes, como explicitado a seguir, levando a uma distorção na Fig.1.

A partir da lista de periódicos disponíveis no portal Qualis, foram selecionados periódicos classificados nas áreas de educação ou ensino como A1, A2, B1, B2 e B3 voltados de forma exclusiva para o ensino de física, ou dedicados às temáticas gerais da física ${ }^{5}$, mas com seções específicas sobre ensino dessa disciplina. Esse recorte foi acrescido de alguns periódicos

\footnotetext{
5 Algumas revistas no segmento Qualis B3 não foram revisadas, pois não possuem o escopo generalista buscado, sendo dedicadas a temas específicos da física (matéria condensada, estado sólido, entre outros). Não consideramos que estas temáticas estejam correlacionadas de forma direta com as aplicações da reflexão no ensino de ciências que pretendemos investigar nesse trabalho. Ademais, as páginas eletrônicas dos periódicos não revelaram nenhuma seção específica dedicada ao ensino da disciplina. Assim, não foram incluídos na revisão os periódicos International Journal of Modern Physics, Physica. B Condensed Matter, Physica. E Low-Dimensional Systems and Nanostructures e Physica Status Solidi B, Basic Research.
} 
específicos do ensino de física que não possuem classificação Qualis, conforme será detalhado a seguir.

Para construir a lista de revistas a serem revisadas, usamos um método misto de busca. Inicialmente, produzimos uma lista com todas as revistas voltadas para educação e/ou ensino com a classificação requerida. A partir dessa lista, procuramos nos títulos dos periódicos a palavra física (ou suas traduções physics e physique). Para uma maior abrangência na revisão, optamos por uma combinação de periódicos de diferentes nacionalidades e vertentes, incluindo publicações em quatro idiomas (inglês, espanhol, francês e português). A lista definitiva é apresentada a seguir:

- American Journal of Physics (A1), EUA;

- Caderno Brasileiro de Ensino de Física (B1), Brasil;

- Caderno de Física da UEFS (B3), Brasil;

- European Journal of Physics (A1), Reino Unido;

- European Journal of Physics Education (sem classificação QUALIS), Turquia;

- Física na Escola (B2), Brasil;

- Gazeta de Física (sem classificação QUALIS), Portugal;

- Latin-American Journal of Physics Education (B1), México;

- Physics Education (A1), Reino Unido;

- Reflets de la Physique (sem classificação QUALIS), França;

- Revista Brasileira de Ensino de Física (A1), Brasil;

- Revista Española de Física (sem classificação QUALIS), Espanha;

- Revista de Enseñanza de la Física (B1), Argentina;

- The Physics Teacher (B1), EUA.

Algumas ressalvas se fizeram necessárias para que a abrangência da base de dados fosse ampliada. A revista portuguesa Gazeta de Física, por exemplo, não consta no portal Qualis, mas é dedicada de forma exclusiva ao ensino de física, especialmente na formação básica, com sugestões interessantes de experimentos e abordagens, de forma similar aos periódicos The Physics Teacher e Física na Escola, daí a sua inclusão na base de revisão.

Também não constam no portal Qualis periódicos franceses ou espanhóis dedicados de forma primária ao ensino de física. Assim, foram adicionadas outras três exceções ao critério de recorte, sendo incluídos o periódico turco European Journal of Physics Education, a revista francesa Reflets de la Physique (editada pela Société Française de Physique) e a ibérica Revista Española de Física (publicada pela Real Sociedad Española de Física). Estes dois últimos periódicos não têm como escopo único a pesquisa em ensino, se dedicando a temas da física em geral, assim como os jornais American Journal of Physics, European Journal of Physics e Caderno de Física da UEFS. Todavia, todas essas revistas publicam artigos dedicados ao ensino de óptica com regularidade, daí a sua inclusão na lista supracitada. Na Revista Española de Física, por exemplo, há uma seção específica voltada para o ensino de física, intitulada "Notas de clase". 
Durante a seleção dos artigos, o portal eletrônico de cada periódico foi consultado de forma individual. No mecanismo interno de busca de cada revista, foi inserido o termo reflexão (ou suas traduções: reflection, reflexión, réflexion). O termo buscado poderia estar presente no título, resumo ou texto completo, para minimizar as chances de exclusão não intencional de artigos.

Em cada portal, a lista de trabalhos resultante foi filtrada por nós de forma "manual": a partir da leitura do título e do resumo do trabalho, buscamos identificar se a sua temática estava vinculada ao fenômeno luminoso, pois a palavra reflexão tem significados múltiplos e, portanto, transparece em diversos contextos. As ferramentas de busca dos periódicos American Journal of Physics, European Journal of Physics, Physics Education e The Physics Teacher permitiram a filtragem por área de estudo (óptica), facilitando a seleção dos artigos. Nos outros periódicos revisados, entretanto, essa característica não estava presente, exigindo um maior esforço para a seleção dos trabalhos adequados.

Nos periódicos brasileiros Caderno Brasileiro de Ensino de Física e Revista Brasileira de Ensino de Física, a busca pelo marcador reflexão retornou um número muito pequeno de artigos, fato considerado estranho por nós, dado que em revisão anterior (RIBEIRO e VERDEAUX, 2012a) já havíamos resgatado um número considerável de artigos dedicados à reflexão da luz. Tornou-se premente então uma consulta mais detalhada, a partir do acesso a cada número individual dessas revistas desde 1995, para que artigos relevantes não fossem desprezados. Assim, foi feita uma leitura dos títulos dos artigos publicados nessas revistas desde esta data, buscando-se identificar quais estariam relacionados ao tema desse trabalho.

A busca pelo termo reflexão no portal da única revista do segmento Qualis B3 incluída nesse trabalho, Caderno de Física da UEFS, não revelou nenhum artigo dedicado a esse tema. Já o sistema de busca da revista Latin-American Journal of Physics Education retornou uma lista de consulta inviável, devido aos critérios internos de indexação dos documentos. Nesse caso, também foi realizada a pesquisa manual nos volumes do periódico, o qual é publicado desde 2007. A revista brasileira Física na Escola não apresenta sistema de busca, obrigando também à consulta individual às edições, as quais foram iniciadas em 2000 e descontinuadas em 2012, sem que haja informações no sítio oficial sobre o retorno das publicações.

A grande transformação induzida na área de publicações acadêmicas pela ascensão da internet como ferramenta de comunicação de massa no final dos anos 1990 pode ser percebida na literatura disponível online. A Revista Española de Física, por exemplo, só disponibiliza suas edições a partir do volume 13, publicado em 1999, quando a revista ganhou uma versão digital. Acreditamos ser provável que os volumes anteriores venham a ser disponibilizados no futuro, após passarem por processo de escaneamento.

A edição digital do caderno argentino Revista de Enseñanza de la Física apresenta uma lacuna nas publicações: os volumes publicados entre os anos de 1993 e 2003 não se encontram disponíveis no sítio da revista. O mesmo se repete com a portuguesa Gazeta de Física: 
embora publicada desde 1946, somente se encontram disponíveis em formato digital os volumes publicados a partir de 1999, além de algumas esparsas edições dos anos 1940 e 1950 . Parece haver, entretanto, um esforço para se disponibilizar tais arquivos históricos em ambos os casos, pois o fato das primeiras edições dos periódicos já se estarem disponíveis parece indicar um processo em curso de conversão digital das revistas impressas.

Pelo exposto, a metodologia de revisão teve que se adaptar às condições de busca de cada periódico, a fim de minimizar as chances de artigos dedicados ao tema não serem incluídos. Admitimos, entretanto, que tal possibilidade de ausência de trabalhos existe, mesmo com todos os esforços citados. Contudo, Braga (1973) nos tranquiliza, em seu trabalho sobre as frentes de pesquisa, as quais devem ser entendidas como o conjunto de artigos mais relevantes em uma área temática. Segundo a autora, uma frente de pesquisa tende a apresentar coincidência com os documentos citados nas revisões de literatura sobre o tema, o que ajuda a minimizar as consequências de eventuais ausências.

\section{Categorias de classificação}

A reflexão da luz é um tema de grande abrangência, incorporando discussões que variam desde princípios físicos fundamentais até temas de alta tecnologia. Assim, decidimos pela categorização dos artigos a partir dos tópicos nos quais a discussão da reflexão é comumente dividida em livros didáticos de ensino superior e médio, com a inclusão de algumas categorias adicionais que emergiram a partir da leitura dos artigos, tais como a refletância e a polarização.

Foram criadas então dez categorias de classificação: princípios da reflexão, refletância, velocidade da luz, reflexão difusa, imagens reais e virtuais, espelhos planos, espelhos curvos, associações de espelhos, polarização e espelhos relativísticos.

Após a separação dos artigos nas categorias que consideramos mais adequadas, percebemos uma grande concentração de trabalhos na classificação de espelhos curvos (cerca de um terço dos artigos). Esta proporção não nos surpreendeu, pois esse tópico permite uma maior variedade de abordagens, fato percebido no maior espaço que os livros didáticos dedicam ao seu tratamento, e também identificado em uma revisão anterior (RIBEIRO e VERDEAUX, 2012a). Cogitamos subdividir essa categoria - por exemplo, em espelhos esféricos, parabólicos, côncavos, convexos - mas percebemos que essa divisão não seria proveitosa, pois exigiria a classificação de alguns artigos em mais de uma categoria, obrigando a mudanças sensíveis na metodologia de revisão.

A Fig. 2 apresenta um gráfico comparando a quantidade de artigos presentes em cada categoria de classificação. Os esforços de revisão levaram à identificação de 152 artigos voltados à reflexão da luz. 


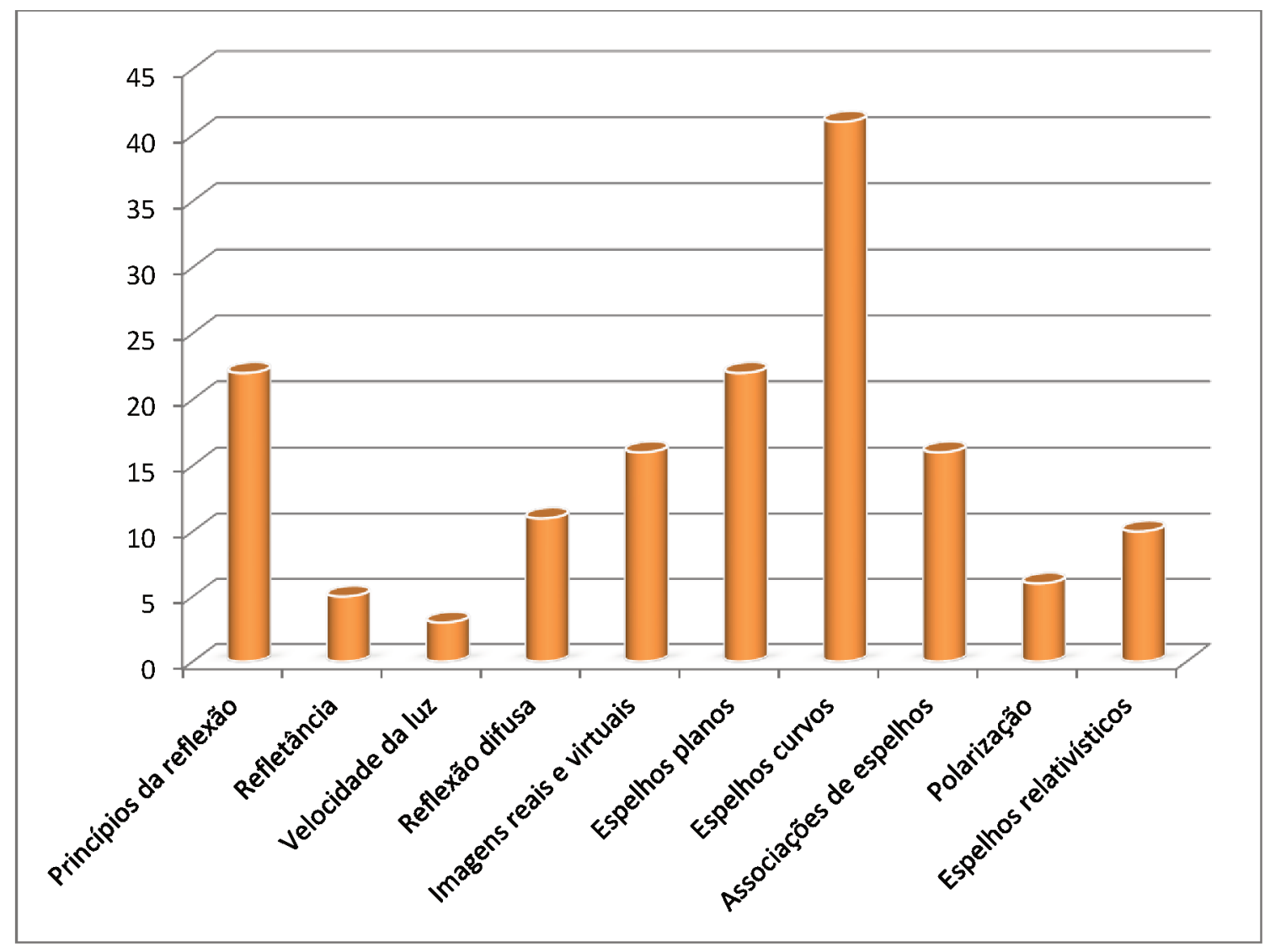

Fig. 2 - Número de artigos incluídos em cada categoria da revisão.

\section{III.1 Princípios da reflexão}

Nessa categoria, incluímos os artigos que se dedicam às leis fundamentais da reflexão, tais como o princípio da igualdade entre os ângulos, o fato dos raios refletidos e incidentes serem coplanares à reta normal e o princípio do caminho mínimo. Artigos que apresentam relatos históricos gerais sobre a óptica, entre os quais a reflexão está incluída, também estão presentes nessa categoria. Reservamos ainda esse espaço para revisões anteriores sobre o tema, mas apenas uma foi identificada na base revisada, o trabalho de Ribeiro e Verdeaux (2012a), o qual apresenta um panorama sobre a pesquisa em experimentação em óptica nos periódicos brasileiros, com um item dedicado aos artigos voltados à reflexão luminosa.

Os princípios da óptica geométrica são eficazes na explicação da reflexão e da refração, mas não são aplicáveis à difração e à interferência, as quais exigem teorias estudadas na óptica física. A proposta de Sharma (2003) busca uma unidade entre essas duas disciplinas, a partir de uma extensão do estudo da interferência em múltiplas fendas. Para o autor, contanto que o espaço entre as linhas seja menor que metade do comprimento de onda da luz incidente, a reflexão e a refração são contempladas pelas mesmas teorias que os outros fenômenos ópticos.

Três artigos se dedicam ao princípio de Fermat, aplicado não apenas à reflexão, mas também à refração. Em sua forma clássica, a qual não cobre todos os casos possíveis, esse princípio conjectura que a luz se propaga de um ponto a outro no mínimo tempo possível. A 
partir dessa afirmação, é possível justificar a necessidade da igualdade entre os ângulos de incidência e reflexão em superfícies planas. Motter (1997) se propõe a apresentar o princípio de Fermat a partir da formulação variacional da óptica geométrica. Essa técnica é usada para encontrar funções matemáticas que possam minimizar ou maximizar os valores de uma variável, e é usada de forma ampla em física, razão pela qual os autores trabalharam com analogias, buscando estabelecer uma ponte conceitual entre a óptica geométrica e a mecânica.

Paleiov et al. (2011) demonstram o princípio de Fermat com um experimento bastante simples, usando um espelho de curvatura arbitrária e fazendo a medição direta dos possíveis caminhos que a luz pode tomar para ir de um ponto a outro após a reflexão no espelho. Os autores apresentam a limitação desse princípio na sua forma clássica, pois na demonstração experimental presente no artigo, a luz toma caminhos que têm máxima ou mínima extensão. Martins e Silva (2013) ressaltam essa limitação, pois o princípio do tempo mínimo só é válido para espelhos curvos convexos. Estes autores utilizam um episódio da história da ciência na sua argumentação, mostrando que esse princípio já era conhecido por Heron de Alexandria no século I, o qual o utilizou para explicar a reflexão em espelhos planos.

Como Martins e Silva (op.cit., 2013) apontam, os princípios fundamentais da óptica têm raízes históricas, sendo natural que trabalhos utilizem a história da ciência como fonte de inspiração. O trabalho de Calvo (2011), por exemplo, faz uma discussão histórica dos currículos universitários espanhóis voltados para o ensino de óptica, incluindo o estudo da reflexão, no início do século XX. É interessante notar que os temas de estudo em cursos de óptica não sofreram grandes alterações desde então, fato que pode ser confirmado ao se comparar os currículos apresentados com a sequência temática dos livros didáticos de ensino superior.

O confronto entre a teoria corpuscular de Isaac Newton e a teoria ondulatória de Christiaan Huygens, desenvolvidas no século XVII6 é subjacente a três trabalhos. Krapas (2011) analisa como a teoria óptica de Huygens está presente nos livros didáticos atuais, concluindo que apenas no tocante à reflexão e à refração há uma correlação entre a teoria histórica e as obras atuais, levando a um tratamento didático ineficiente. Silva (2011) também se dedica ao tema da transposição didática das ideias de Huygens em livros de ensino médio, mas expande sua discussão para sites da internet. Já Moura e Silva (2008) expõe uma conjectura ousada, a nosso ver, em seu artigo: os autores questionam se os trabalhos de Newton teria antecipado o conceito de dualidade onda-partícula. Afinal, para explicar a reflexão e a refração, Newton se apoia na teoria corpuscular, mas parece deixar espaço para propriedades "periódicas" da luz ao lidar com os anéis de Newton, fenômeno ligado à interferência luminosa e que demanda a teoria ondulatória para ser explicado. A conjectura é falseada no próprio artigo, que analisa fontes primárias e secundárias para demonstrar que Newton não aceitava o modelo dual para a luz.

\footnotetext{
${ }^{6}$ Newton desenvolveu sua teoria óptica no século XVII e publicou diversos textos sobre o tema durante essa época. Entretanto, ele condensou suas ideias no seminal livro Opticks: or, a treatise of the reflexions, refractions, inflexions and colours of light (NEWTON, 1730), publicado no século posterior.
} 
Referências históricas também formam o escopo do trabalho de Moura e Boss (2015), que apresentam uma tradução comentada do artigo de Thomas Young, On the theory of light and colour, publicado originalmente nas Philosophical Transactions da Royal Society de Londres, em 1802. No artigo, Young apresenta a interpretação ondulatória para a natureza da luz, a qual viria a se tornar dominante ao longo do século XIX, discutindo suas aplicações em diversos fenômenos ópticos, entre os quais a reflexão luminosa. Martins e Silva (2015), por sua vez, rediscutem o contexto em que se desenvolveu a óptica newtoniana, apresentando um detalhado relato histórico acerca dos conceitos anteriores aos trabalhos de Isaac Newton. Comparações e conexões entre a óptica geométrica (de base newtoniana e gaussiana) e o modelo ondulatório são discutidas para a reflexão, refração e difração no trabalho de Souza et al. (2015).

Uma preocupação comum a alguns autores é a apresentação de estratégias diferenciadas dos princípios da reflexão e da óptica em geral. A experimentação se inclui nessas estratégias: Silva (2004), por exemplo, apresenta um projeto para a construção de um banco óptico composto de materiais de baixo custo, que pode ser utilizado em aulas experimentais de reflexão e refração no ensino médio. A proposta de Camargo et al. (2008) também envolve a construção de artefatos concretos, mas para a exposição dos princípios ópticos para alunos com deficiência visual, razão pela qual os artefatos são tátil-visuais. Robinett et al. (1998) também apresentam um experimento, com grande potencial lúdico, no qual múltiplas reflexões de um feixe de laser são obtidas, em uma analogia mecânica com uma hipotética mesa de bilhar circular.

O problema conceitual discutido por Rojas (2013) diverge da experimentação. O autor se dedica a explicar a multiplicidade de convenções de sinais usadas na óptica de espelhos e lentes, pois pelo menos quatro convenções diferentes são usadas, fato que traz dificuldades à aprendizagem, segundo o autor.

Princípios fundamentais são searas férteis de discussão em qualquer área científica. Artigos podem buscar sua confirmação, refutação, generalização, reelaboração, entre outras possibilidades. Observamos em um grupo de textos estas linhas de trabalho. Bhattacharjee (2005), por exemplo, relata a generalização das leis da reflexão e da refração da luz a partir de um tratamento vetorial e de uma recategorização das definições de ângulo de incidência, reflexão e refração, entendidas como ambíguas pelo autor. Hawkes (2014) não chega a refutar as argumentações de Bhattacharjee, mas também não as considera como novidades, já que as mesmas podem ser encontradas em outros textos de óptica.

Sugon e McNamara (2004) também perseguem uma reformulação dos princípios fundamentais da óptica, incluídos aqueles voltados à reflexão, mas usando um modelo baseado na álgebra de Pauli, a qual permite que as leis da reflexão e da refração sejam reescritas de forma exponencial e se apresenta equivalente às considerações vetoriais. Aguiar (2009) já propõe reescrever os princípios da óptica em simulações computacionais de geometria dinâmica, sugerindo que algumas dificuldades conceituais que os estudantes tradicionalmente encontram nessa 
disciplina podem ser superadas com a ajuda dessa modelagem. Exemplos de aplicação são apresentados para a reflexão e refração.

Embora o princípio da igualdade dos ângulos de incidência e reflexão seja válido para qualquer geometria, ele pode se revelar complexo para espelhos curvos. Assim, é comum que este princípio seja substituído pela consideração de raios paraxiais (próximos ao eixo principal do espelho), conhecida como uma das condições de aproximação de Gauss. Şengören e Çoban (2011) se dedicam a essa condição, apresentando um experimento simples, usando um laser e uma superfície côncava cilíndrica, para a verificação da posição do foco dos raios paraxiais e da obtenção de múltiplas imagens quando essa condição de aproximação não é verificada. Já Liñares e Nistal tomam o caminho oposto à simplificação, e desenvolvem um tratamento matemático intenso sobre as leis geométricas baseadas na condição de raios paraxiais, mas a partir do modelo ondulatório para a luz.

O artigo de Hendry (2003) apresentou dificuldades para a sua classificação, por lidar com um fenômeno cuja explicação é associada à refração: o arco-íris. Entretanto, a abordagem do autor envolve o princípio da igualdade dos ângulos na reflexão, razão pela qual decidimos pela inclusão desse artigo no item presente. $\mathrm{O}$ autor discute a existência de um arco-íris triplo, e demonstra a possibilidade de sua existência de forma algébrica; entretanto, o próprio autor não conseguiu demonstrá-la de forma experimental, pelas dificuldades inerentes ao fenômeno 7 .

\section{III.2 Refletância}

Nenhum material conhecido reflete a luz em sua totalidade, pois parcelas dessa radiação são absorvidas ou transmitidas pela substância. Assim, a refletância de um material ou superfície pode ser entendida como a razão entre a intensidade da radiação refletida e a intensidade da radiação incidente. Essa grandeza é dependente do comprimento de onda da luz e do ângulo de incidência (BOULOMYTIS et al., 2011). A transmitância é uma grandeza correlacionada, entendida como a razão entre as intensidades da luz transmitida (ou refratada) e incidente.

Um subconjunto dos artigos revisados se dedica às pesquisas teóricas e experimentais acerca dessa grandeza. Esse grupo apresentou como principais características o intenso tratamento conceitual e a exposição de sugestões de minimização das dificuldades técnicas para a medição da refletância.

Roeder (2012) desenvolve o trabalho menos desafiador, mostrando como o uso de espelhos refletores comuns, cuja refletância pode ser entendida como constante e independente

\footnotetext{
${ }^{7}$ A defesa teórica do artigo é verdadeira, fato hoje facilmente confirmável: a busca pelo termo "triple rainbow" na internet revelou diversas imagens do fenômeno. Até mesmo arco-íris quádruplos já foram fotografados, e.g. $<$ http://news.nationalgeographic.com/news/2011/10/pictures/111007-first-quadruple-rainbow-triple-science-optics $/>$.
} 
do comprimento de onda incidente, aumenta a taxa de iluminação de uma lâmpada. Essa aparente simplicidade contrasta com o artigo de Boulomytis et al. (2011), que se preocupa em apresentar uma metodologia experimental para o entendimento dos princípios físicos referentes à refletância e transmitância de uma superfície, com rigor matemático e experimental.

Refletância e transmitância são conceitos inter-relacionados, sendo natural que artigos se dediquem a ambos. Encontramos um exemplo dessa dupla abordagem em Kokhanovsky (2001), que trabalha com as propriedades ópticas de meios turvos, tais como suspensões concentradas ou pastas. Já o artigo de Iwanaga et al. (2007) aborda os temas da refletância e transmitância recíprocas, os quais remontam aos trabalhos de Fizeau no século XX. Os autores apresentam uma nova prova considerada "elementar" para esses fenômenos. Para esses fins, é desenvolvida uma abordagem teórica e uma sugestão de experimento, linha de trabalho seguida também por Vieira (2014), o qual propõe um aparato experimental simples (do ponto de vista do autor) para medir a dependência da refletância com o ângulo de incidência da radiação.

\section{III.3 Velocidade da luz}

No século XIX, os métodos desenvolvidos por Hippolyte Fizeau e Léon Foucault se destacaram para a determinação experimental da velocidade da luz. Embora esses cientistas tenham trabalhado juntos em outras ocasiões, eles seguiram caminhos diferentes no que tange a essa medição (HUGHES, 2012).

Ambos os aparatos experimentais desenvolvidos por Fizeau e Foucault envolviam espelhos para a sua construção, como estratégia para tornar mais longo o caminho da luz e assim tornar as medições mais fáceis e precisas. No experimento de Fizeau, a luz emitida por uma fonte era dividida por um espelho semitransparente, e um dos raios obtidos era refletido por outro espelho, disposto a vários quilômetros de distância, retornando para o observador após passar por uma roda dentada. Já na montagem de Foucault, a roda dentada estava ausente, mas a primeira reflexão era produzida por um espelho plano em rotação (op.cit., 2012).

Um pequeno conjunto dos artigos revisados se dedica a propor recriações didáticas dos aparatos desenvolvidos por esses dois pesquisadores, incorporando discussões sobre a reflexão da luz nos textos. Morizot et al. (2011) descreve uma recriação do experimento de Fizeau, a qual foi conduzida para fins didáticos, usando um laser refletido por um espelho no centro da cidade francesa de Marseille. O experimento trouxe resultados com baixa incerteza, atribuída a flutuações no índice de refração do ar.

As duas reconstruções do método de Foucault propostas por Vörös e Weihs (2015) são mais compactas e podem ser feitas em um laboratório universitário de física. Como é tradicional em projetos de ensino experimental, o aproveitamento de sucatas para minimização dos custos está presente neste trabalho: o espelho giratório foi retirado de uma impressora laser desativada. Ortiz e Montecinos (2015) também apresentam uma alternativa para essa medição, desenvolvendo um circuito de baixo custo, mas também envolvendo a reflexão da luz de um laser em 
um espelho como nas propostas anteriores. Ambas as sugestões levam a resultados de boa precisão para a velocidade da luz, demonstrando o potencial didático das mesmas.

\section{III.4 Reflexão difusa}

O estudo dos espelhos de diversas geometrias é quase um sinônimo da abordagem que os livros didáticos desenvolvem nos capítulos voltados à reflexão óptica. Menor destaque merece o fenômeno da reflexão difusa, talvez pelas dificuldades em analisar esse tema de forma quantitativa.

A reflexão é dita especular quando ocorre em superfícies lisas, tais como espelhos, e difusa em superfícies irregulares (GUIMARÃES et al., 2013). As irregularidades terminam por espalhar a luz incidente em diversas direções, permitindo que o observador veja a própria superfície e não uma imagem da fonte luminosa. Nesse aspecto, a reflexão difusa é muito mais comum que a especular: quando olhamos para a maioria dos objetos cotidianos, estamos captando a luz difundida por suas superfícies.

Esta separação entre reflexão especular e difusa, evidenciada nos textos de obras didáticas, é posta em xeque por Fakhruddin (2007). O autor demonstra por via experimental que superfícies irregulares podem vir a produzir as imagens virtuais típicas da reflexão especular, contanto que o ângulo de incidência seja alto, ou seja, os raios sejam praticamente paralelos à superfície.

A reflexão difusa não é produzida apenas por irregularidades na superfície do material. Berry e Klein (1997) apresentam uma interessante aplicação desse fenômeno, conseguida quando são empilhadas diversas lâminas plásticas de espessuras variadas, tais como as antigas transparências de retroprojetores. Os autores demonstram que quase toda a luz incidente é difundida por reflexão, devido à acumulação das reflexões nas várias interfaces entre as lâminas, entre as quais uma fina camada de ar é acumulada.

Um erro conceitual comum por parte dos estudantes é associar a difusão da luz a uma violação do princípio da igualdade dos ângulos de incidência e reflexão. Esse princípio é obedecido em qualquer reflexão, mas a irregularidade da superfície faz com que os ângulos de incidência sejam diferentes em cada ponto, mesmo para os raios solares (supostos paralelos). Essa preocupação aparece no artigo de Alloco (1999), dedicado a um exemplo prosaico desse fenômeno: a reflexão difusa da luz em uma poça de água agitada pela chuva, tornando impossível observar a imagem refletida do céu. O fenômeno pode parecer banal, mas Molesini e Vannoni (2008) discordam. Os autores analisam a situação em detalhe, usando um modelo simplificado e simétrico das ondas formadas na superfície da água quando gotas de água incidem sobre a mesma, e mostram evidências de padrões de distorção na luz difundida pela superfície. Os mesmos autores (MOLESINI e VANNONI, 2009) expandem a discussão em um artigo posterior, levando em conta configurações assimétricas, a fim de determinar uma solução mais geral para os padrões de reflexão observados. 
A busca de padrões na reflexão difusa também é a preocupação de dois outros trabalhos, nos quais ambos os autores lidam com a difusão da luz de um laser, que após incidência em uma superfície irregular, é projetada em uma tela. As linhas de investigação, entretanto, são diferentes: enquanto Gonzáles et al. (1999) analisa os padrões de interferência resultantes da incidência do laser em um espelho "empoeirado", com rigor matemático e experimental, Ennos (1996) se dedica a evidenciar as propriedades da luz que podem advir dessa experimentação, sugerindo inclusive um aparato experimental para a detecção de processos visuais falhos nos observadores.

Apesar de alguns dos artigos supracitados terem vertentes teóricas, percebe-se da leitura dos artigos que a análise qualitativa de situações cotidianas é a principal linha de condução dos artigos incluídos nesse item. Zanardi e Muramatsu (2011), por exemplo, explicam as manchas esbranquiçadas na superfície do café como um resultado da reflexão difusa das múltiplas frequências que compõem a luz branca. Mohammadpour (2008) usa a face impressa de um compact disc (CD) para demonstrar a difusão: após refletir a luz de uma lanterna nessa face, as áreas prateadas da superfície são projetadas em um anteparo como claras, enquanto as áreas impressas aparecem escuras, pois a luz refletida nessas áreas foi espalhada em direções diversas. Já Tantillo (2008) apresenta uma discussão sobre uma ilusão de óptica, relacionada à difusão da luz, produzida quando dois blocos de parafina são separados por papel alumínio. A nosso ver, essa última atividade tem forte potencial didático, pela sua simplicidade e efeito lúdico.

Por vezes, esse caráter lúdico das propostas transparece até mesmo no título dos artigos: o título do artigo de Grossman (2014) nos leva a acreditar que o autor está estudando como vampiros produzem suas selfies! A leitura do texto, entretanto, mostra a seriedade do tema, pois a imagem de uma pessoa pode se revelar ausente quando produzida por metais escovados, como aqueles usados em revestimentos de paredes em elevadores. A difusão da luz nessas superfícies leva ao "desaparecimento" da imagem do observador, daí a alusão à selfie vampírica.

\section{III.5 Imagens reais e virtuais}

A reflexão especular, em última instância, permite a conjugação de imagens ópticas. Há dois tipos de imagens em óptica: reais, resultantes da convergência de raios de luz emergentes de um espelho ou outro sistema óptico, e virtuais, resultantes da divergência dos raios. A imagem que uma pessoa observa de si própria em um espelho plano é virtual, enquanto um espelho côncavo pode ser usado para projetar uma imagem real e invertida de uma vela em uma parede.

Um subgrupo dos artigos revisados se dedica de forma prioritária à análise de como essas imagens são produzidas e quais as características das mesmas, usando diferentes tipos de espelhos. O trabalho de Küçüközer (2011) busca evidenciar as diferenças entre os dois tipos de imagem. Segundo o autor, os estudantes acreditam que uma imagem real só pode ser vista se for projetada em uma tela, fato que não é verdadeiro, mas que leva a erros conceituais graves, como a crença de todas as imagens vistas diretamente terem caráter virtual. 
Essa crença errônea pode ter sua origem nos próprios experimentos conduzidos pelos professores em sala de aula, como o sugerido por Graham (2006), que usa um trilho óptico simplificado e um espelho côncavo, para projetar a imagem real de uma lâmpada abaixo da mesma. Sem uma explicação adicional sobre a possibilidade de a imagem ser vista sem a projeção, o estudante pode associar os dois fenômenos de forma indelével. Balta e Eryilmaz (2011) também se dedicam a explicar a diferença entre imagens reais e virtuais, a partir da prosaica imagem invertida que se pode observar na superfície côncava de uma colher. Os autores relatam ter encontrado na internet diversas explicações errôneas para o fenômeno, razão que os motivou a desenvolver a explicação correta.

O artigo de Silva (2011) nos chamou a atenção por razões inusitadas. O trabalho expõe uma técnica para produzir hologramas no ensino médio e compará-los com a formação da imagem virtual em um espelho plano. Segundo o autor, o custo para o desenvolvimento dessa atividade é baixo, pois os materiais necessários foram adquiridos por uma quantia inferior a 500 euros. Como a pesquisa de Laburú (2005) explicita, um dos fatores priorizados por professores de física na seleção de atividades experimentais é o baixo custo, mas percebe-se que o valor estabelecido como baixo é diferente para cada pesquisador.

As imagens formadas por espelhos planos apresentam a propriedade do enantiomorfismo: a imagem de um objeto se apresenta reversa em relação a ele, com o espelho funcionando como plano de simetria. Segundo o artigo de Providência (2009), é simples perceber esse fenômeno olhando para as próprias mãos, pois a mão esquerda é enantiomorfa (ou quiral) da direita. O artigo de Deweerd e Hill (2004) trata não apenas da simetria, mas também da lateralidade observada na imagem, ou seja, se as imagens observadas em espelhos de formatos diversos (côncavo, convexo, plano) sofrem rotação em algum eixo, quando observadas ou projetadas.

Já Daffron e Greenslade Jr. (2015) utilizam as imagens virtuais para a detecção de padrões complexos de vibração em um caleidofone (aparelho capaz de gerar uma multiplicidade aleatória de sons, assim como o caleidoscópio cria uma diversidade de imagens). Os autores destacam, entretanto, que o caráter virtual obriga o observador a se dispor em uma posição adequada para enxergar o padrão de vibração, fato que não aconteceria caso a imagem gerada fosse real e estivesse projetada em um anteparo.

A comparação entre hologramas, imagens estereoscópicas e imagens ópticas tradicionais também aparece no artigo de Lunazzi et al. (2010), que descreve uma atividade de extensão universitária sobre o tema, voltada para alunos de ensino médio, com vistas a suprir as deficiências observadas nas práticas de laboratório da cidade de Campinas, atribuídas pelos autores à carência de recursos financeiros e atribuição ao ensino médio de um papel de mera "porta de entrada para a universidade", tornando injustificada a presença de atividades experimentais nessa fase de ensino, visão não corroborada pelos autores.

A característica de simetria entre imagem e objeto também é utilizada por alguns autores em analogias entre a óptica geométrica e vertentes artísticas, como a arte étnica da Índia e algumas regiões da África (BAPAT, 2009) e os tradicionais azulejos decorativos, introduzidos 
pelos árabes em Portugal (PROVIDÊNCIA e PROVIDÊNCIA, 2014). Analogias também estão presentes no trabalho de Moore et al. (2011), no qual o conceito de imagens virtuais é explorado a partir do movimento de bolas em uma mesa de bilhar, o qual é comparado pelos autores com o traçado de raios de luz na óptica geométrica.

Como discutido por Küçüközer (op. cit., 2011), as imagens reais podem ser observadas sem a necessidade de projeção. O uso de um equipamento comercial composto de dois espelhos côncavos, o mirascópio, já é tradicional como atividade experimental demonstrativa para a visualização de uma imagem real tridimensional de um pequeno objeto. Featonby (2007) ressalta que esta imagem pode se tornar ainda mais "real" se a luz emitida por uma lanterna ou apontador laser for direcionada para a posição de formação dessa imagem.

A construção geométrica de imagens em espelhos envolve os tradicionais diagramas de raios de luz, sobre os quais discorre Maiztegui et al. (1998). Estes autores defendem que a abordagem tradicional da óptica no ensino médio supervaloriza tais construções, relegando a prática experimental a segundo plano, daí a apresentação de uma proposta experimental simples no artigo para complementar o processo tradicional de construção geométrica. O artigo de Santana et al. (2012) também se dedica a esses diagramas, ressaltando seu potencial para entendimento e caracterização das propriedades dos sistemas ópticos, mas ressalvam as dificuldades conceituais que os estudantes apresentam ao lidar com esses processos construtivos. Para os autores, essas dificuldades se originam na representação da propagação das ondas luminosas por raios de luz, as quais podem ser minimizadas com o uso de simulações computacionais, baseadas no sistema GeoGebra, posição compartilhada por Chirino et al. (2015), os quais discutem a eficácia do uso de softwares de simulação do traçado de diagramas ópticos para a aprendizagem significativa.

Relatos de pesquisas sobre imagens ópticas na reflexão e refração inspiradas a partir de relatos da história da ciência se revelaram escassos: apenas Mihas (2008) utiliza tal abordagem, mas de forma bastante completa, conduzindo uma discussão histórica que se inicia com as especulações de Platão sobre a natureza das imagens em espelhos, avançando pelos estudos de Ptolomeu e Euclides sobre os raios visuais, ressaltando em seguida as contribuições dos árabes e encerrando com as teorias de Kepler, Huygens e Fermat sobre o tema.

\section{III.6 Espelhos planos}

Espelhos planos permeiam a vida cotidiana, fato ao qual atribuímos a variedade de propostas didáticas sobre os mesmos. Os artigos incluídos nesse item apresentaram, em linhas gerais, um menor grau de rigor algébrico, com propostas mais adequadas ao ensino médio. Alguns artigos que incluíam espelhos planos em seus estudos foram revisados em outros itens, por se dedicarem de forma mais sensível à formação de imagens ou aos princípios da reflexão, por exemplo.

A onipresença desses instrumentos ópticos na vida diária pode levar um professor de física a acreditar que seus estudantes terão facilidade em compreender a formação de imagens 
nos mesmos. Mansell (2007) discorda dessa visão, propondo uma atividade bastante simples para demonstrar a posição da imagem em um espelho plano, utilizando um CD para tal. Gluck (2002) também propõe a experimentação com CDs, mas ressaltando que esses dispositivos podem ser usados como redes refletoras difrativas.

O artigo de Baird (2014) rediscute um problema didático clássico: o cálculo do espelho de mínimo tamanho para que uma pessoa observe sua imagem de corpo inteiro, para mostrar o quanto o ideário discente pode se enganar nesse tópico. O intrigante questionamento do autor versa sobre o tamanho necessário para que uma pessoa pudesse ver a sua imagem por completo, como no problema didático, mas considerando o observador em pé na Lua. É conduzida uma prova algébrica simples e uma sugestão de experimentos, onde a imagem do observador em um espelho distante é vista através de uma luneta, para a demonstração não intuitiva sobre o tamanho constante do espelho (igual à metade da altura do observador) para essa visualização de corpo inteiro, independentemente da distância entre o observador e o espelho.

Espelhos planos formam imagens simétricas e enantiomorfas (reversas) em relação ao objeto original. Yurumezoglu (2009) acredita que essa é uma característica que não deve ser tratada pelo professor apenas de forma abstrata, dadas as possibilidades de entretenimento, descoberta e investigação subjacentes ao tema. $\mathrm{O}$ autor propõe uma atividade bastante simples para o estímulo dessas possibilidades, onde imagens de objetos planos e tridimensionais em um espelho plano são comparadas entre si. Para melhor entendimento dos princípios da reflexão e das características da imagem em um espelho plano, Yurumezoglu e Oguz-Unver (2010) propõem partir o espelho em diversos espelhos menores, permitindo diversas configurações desses elementos, para que os estudantes possam conduzir suas próprias investigações a respeito da maneira como as imagens são formadas em um espelho plano.

O caráter lúdico das atividades envolvendo esses elementos ópticos emerge também nos trabalhos de Gardner (1999) e Thompson e Mathieson (2001), que apresentam duas propostas simples para criar a sensação de que um objeto está levitando no espaço. Gough (2006) já utiliza um disco de vinil e uma fonte de luz para criar um efeito de um feixe luminoso tridimensional cruzando o centro do disco. Carlson (2014) destaca outra aplicação desses elementos, não pelo seu caráter lúdico, mas utilitarista: na Segunda Guerra Mundial, os soldados americanos receberam um espelho de sinalização, um equipamento bastante simples, de tamanho equivalente a um cartão de crédito atual. O aparato era composto de um espelho plano do qual era retirada uma pequena cruz na área central. Em caso de necessidade de resgate, o soldado deveria usar o espelho para direcionar os raios de luz solar para um avião de resgate, a fim de que sua localização pudesse ser estabelecida pelo piloto. A cruz servia como visor, garantindo o alinhamento da luz do sol com o avião.

Os trabalhos de Silveira e Axt (2001) e Silveira e Axt (2007) trabalham o mesmo tema: a projeção da luz do Sol a partir do uso de espelhos planos, em especial o caso particular da projeção da imagem do Sol durante um eclipse. O trabalho de Silveira e Axt (op. cit., 2001) afirma que a partir de uma montagem apropriada, utilizando-se apenas espelhos planos, pode- 
se observar uma imagem real do Sol e até mesmo projetá-lo durante um eclipse, sem risco para os observadores. Essa proposta é corroborada por Bartlett (1996), que demonstra em que condições um pequeno espelho plano pode ser usado como para fins de projeção, de forma análoga a uma câmara escura. Nessas situações, o espelho plano está projetando uma imagem real, possibilidade raramente discutida nos livros didáticos, mas ressaltada por Silveira e Axt (op. cit., 2007).

Dois autores discutem a mesma atividade experimental: a projeção da sombra de uma imagem virtual, com a consequente produção de uma sombra dupla. Para conseguir esse efeito, basta que um objeto vertical esteja disposto sobre um espelho plano horizontal, iluminado pela luz solar, e haja uma parede vertical próxima. Russel (2010) obtém tal efeito com uma lâmina de vidro como espelho, enquanto Cepic (2006) utiliza um espelho tradicional e a luz emitida por um retroprojetor em substituição da radiação solar, para que o experimento possa ser conduzido em um ambiente interno, como um laboratório ou sala de aula.

Um grupo de artigos se destacou nesse item por se dedicar a um tipo de espelho desconhecido por nós, o "espelho mágico" chinês (ou oriental). Conforme Mills (2011) explica, tais "espelhos mágicos" são peças metálicas planas de bronze, esculpidas com algum motivo gráfico em um único lado. Entretanto, se tais peças forem iluminadas pelo seu lado oposto (não esculpido), a luz refletida pode ser projetada em uma parede, e uma imagem do motivo esculpido é visível nessa parede. Daí a nomenclatura de "espelhos mágicos", devido a essa incomum propriedade óptica. Um exemplo desse inusitado aparato é apresentado na Fig. 3.

Mills (op. cit., 2011) explica a natureza do fenômeno dos espelhos mágicos, a qual está associada a ponto de pressão que são criados na face oposta durante o processo de polimento. O autor demonstra ser possível reproduzir o efeito com medalhões de latão baratos. Os artigos de Tao e Lee (1997) e Berry (2005) também trabalham com os espelhos mágicos orientais, sendo a abordagem do primeiro artigo voltada para as aplicações didáticas, enquanto a proposta do último envolve um tratamento conceitual mais rigoroso da formação dessa imagem.

Três artigos exploraram a obtenção de franjas de interferência com espelhos planos. Esse experimento é conhecido como "espelho de Lloyd", em reconhecimento à descrição conduzida por Humphrey Lloyd em 1837. Quando um espelho plano comum é iluminado por um laser, ocorre interferência entre a luz refletida pela fronteira entre o vidro frontal e o ar e aquela refletida pela película metálica que recobre o fundo do vidro. Projetando-se os feixes de luz em uma parede, são observadas áreas claras e escuras espaçadas, típicas do fenômeno da interferência. 


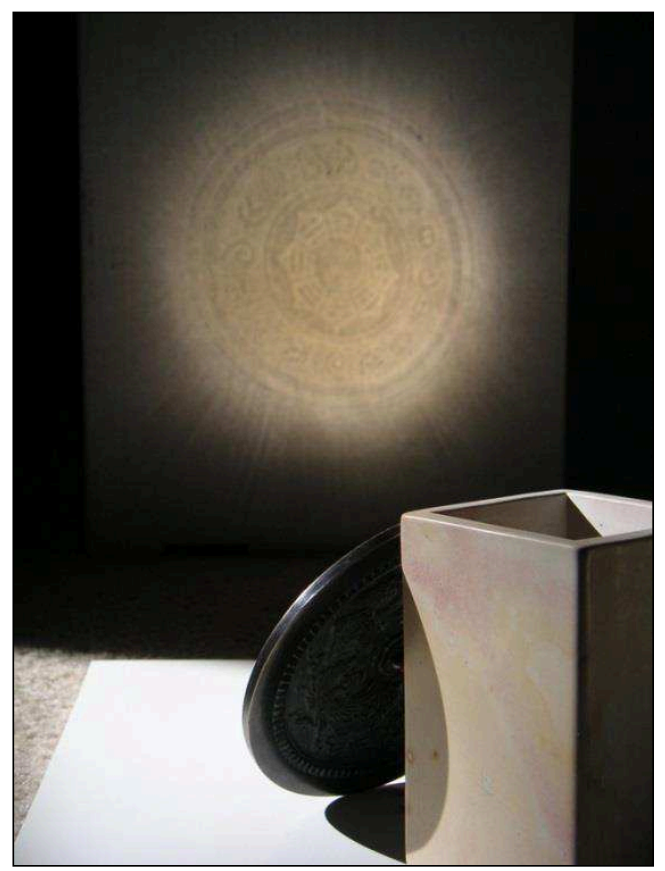

Fig. 3 - "Espelho mágico" oriental. Fonte:

<https://lemurking.files.wordpress.com/2008/09/magic-mirror.jpg>. Acesso em: 01 nov. 2015.

Cavalcante e Rodrigues (2012) defendem que essa é uma experiência ótima para demonstrar a reflexão e a interferência em sala de aula, tanto do ponto de vista qualitativo quanto quantitativo, mas encaram que o potencial didático da mesma é mal aproveitado. Catelli e Lazzari (2004) desenvolvem a mesma atividade experimental, mas fazem uma pequena modificação, retirando a lente colimadora do apontador laser e usando uma lâmina de vidro comum ao invés do espelho. De acordo com os autores, os resultados obtidos são "empolgantes", devido ao intenso contraste entre as áreas claras e escuras e também pelo fato dos alunos poderem perceber que a interferência ocorre a partir de duas fontes luminosas, o objeto real e sua imagem virtual. Uysal (2010) também trabalha com o mesmo experimento, mas com a intenção de descobrir o índice de refração do vidro que compõe o espelho.

Apenas dois artigos se revelaram mais desafiadores em termos algébricos. O trabalho de Erb (1997) utiliza uma proposta de Feynman para descrever a luz por meio de fasores, em um sistema que incorpora características tanto do modelo ondulatório quanto do corpuscular para a luz. Já Bernal e Bilbao (2007) estudam o efeito Doppler luminoso (mudança aparente de frequência devido ao movimento relativo entre a fonte e o observador) a partir de um espelho em rotação. A nosso ver, as propostas desses autores são mais adequadas para o ensino superior. 


\section{III.7 Espelhos curvos}

Há dois tipos básicos de espelhos curvos: côncavos (como um espelho de aumento) e convexos (como um retrovisor de bicicleta). A forma geométrica também é levada em conta na nomenclatura de tais espelhos, existindo espelhos esféricos, elípticos, parabólicos, hiperbólicos, entre outros.

Devido à grande variedade de aplicações, é nesse tópico que se concentram as pesquisas sobre reflexão. Se levarmos em conta que alguns dos artigos citados no item 3.8 (imagens reais e virtuais) utilizam espelhos curvos em suas montagens ou explicações, mais de um terço dos artigos revisados trabalha com esses elementos ópticos.

Nos livros-texto de física de ensino médio, espelhos curvos com geometria diferente da esférica são discutidos de forma esparsa. O tratamento aproximado para a formação de imagens em espelhos esféricos é baseado nas condições de aproximação de Gauss, que levam em conta a necessidade de raios paraxiais (próximos ao eixo principal) e o grau de curvatura do espelho ser pequeno (RIBEIRO, 2015b). Por vezes, espelhos com formatos diferentes nem mesmo são citados, como nos textos de Bonjorno et al. (2010) e Guimarães et al. (2013). Outros livros (ANJOS, 2005; RAMALHO et al., 2007) fazem referência apenas a espelhos esféricos, mas ao apresentarem fotografias das trajetórias de reflexão de raios paralelos paraxiais, os espelhos mostrados são cilíndricos.

Alguns dos artigos incluídos nesse item se preocupam em expandir a discussão didática tradicional, mas sem a introdução de novos conceitos para o estudante. Esse é o caso do trabalho de Erb (1995), que utiliza o clássico experimento de observação da imagem de uma vela à frente de espelhos planos e côncavos para discutir os princípios fundamentais da reflexão e a formação de imagens. Já Silveira et al. (2004) apresenta situações onde as imagens ditas invertidas, as quais são produzidas por espelhos côncavos, se apresentam direitas ao observador, dependendo da posição em que o olho esteja localizado. Uma adequada posição do observador permite que ele visualize uma imagem direita e menor que o objeto, não discutida pelos livros didáticos. Korsunsky (2005) apresenta outro problema clássico: como descobrir a posição da imagem quando água é colocada na superfície de em um espelho côncavo.

Adie (1997) também não busca desafiar os estudantes, apresentando um aparato bastante simples, construído com um apontador laser e um espelho plástico curvo, o qual permite demonstrar com facilidade a convergência ou divergência dos raios de luz após a reflexão, permitindo que o estudante perceba que os raios se afastam ou se aproximam em uma direção perpendicular à propagação, em um paralelo com a representação geométrica tradicional dos livros didáticos. Preocupações pedagógicas também estão no cerne do artigo de Greenslade Jr. (2000), no qual é descrita uma aula experimental sobre a geometria de espelhos curvos para estudantes universitários de áreas não científicas. $\mathrm{Na}$ atividade proposta pelo autor, os próprios estudantes executam o traçado dos raios que incidem em espelhos curvos (feitos de lâminas plásticas que podem ser curvadas com facilidade), acompanhando com o lápis a "trajetória" tomada pela luz emitida por um laser. 
Libertun (2003) discute outro exemplo costumeiro de uso de espelhos convexos no cotidiano: os espelhos retrovisores do lado direito dos automóveis (passageiro) e a mensagem "misteriosa" que alguns deles trazem ("Cuidado! Os objetos no espelho estão mais próximos do que parecem!’”. $\mathrm{O}$ autor apresenta as razões físicas que explicitam esse alerta, a partir do conceito de campo visual, conceito que costuma se restringir ao caso particular do espelho plano nos livros-texto de ensino médio. Salinas e Sandoval (2000) apresentam uma visão qualitativa como complementação dessa abordagem tradicional, trabalhando com a construção de campos visuais em espelhos curvos. Estes autores defendem que esse método de construção qualitativa pode levar os estudantes a entender melhor a formação de imagens parciais de um objeto, situação muito frequente na vida cotidiana e não apresentada em livros-texto. Por sua vez, De Jesus e Sasaki (2013) optam por interpretar as imagens observadas em espelhos esféricos côncavos a partir do conceito de aumento angular, pouco discutido nas obras didáticas.

As diferenças entre as imagens conjugadas por espelhos côncavos e convexos também se revelam onipresentes nas abordagens trazidas pelos livros didáticos. Deweerd e Hill (2005) contextualizam essa diferença de forma criativa, a partir da análise qualitativa das imagens observadas na superfície do chá em uma xícara. Os movimentos nessa superfície produzem imagens de fontes luminosas próximas que podem ser explicados a partir dos modelos tradicionais de construção geométrica presentes nos livros-texto.

A sugestão de experimentos de baixo custo também se revela presente em alguns artigos. O trabalho de Almeida et al. (2013) apresenta uma proposta para produção de um conjunto didático para o estudo de espelhos esféricos, a partir do reaproveitamento de vidros de relógio, o qual permite boa qualidade nas imagens produzidas e determinação de dados quantitativos. Já Catelli e Reis (2004) trabalham com a reflexão da luz no bulbo de uma lâmpada incandescente, demonstrando a formação de duas imagens (uma real e outra virtual) no interior da lâmpada, pois o bulbo se comporta como dois espelhos independentes, um côncavo e um convexo. Esse trabalho encontra eco em diversos artigos. Keeports (2005) mostra que essas mesmas imagens, uma real e outra virtual, também são conjugadas por uma lente convergente de Fresnel retirada de um retroprojetor; Ribeiro (2013) expande a proposta, mostrando que quatro imagens são formadas por reflexão em uma taça de vinho, e Toepker (2014) discute a visualização das quatro imagens de Purkinje no olho humano, as quais são formadas por reflexão na córnea, de maneira similar àquelas observadas na taça.

Alguns artigos se preocupam com o estudo dos instrumentos ópticos que têm como princípio de funcionamento a reflexão luminosa, em especial os telescópios. A construção pelos próprios estudantes de telescópios simples é incentivada: Bernardes et al. (2006) ressaltam os benefícios que a construção de telescópios pode trazer para o aprendizado da Óptica no ensino médio (tipo newtoniano) e superior (tipo cassegrain). A utilização dos instrumentos construídos em observações astronômicas reais também é defendida como seara de aprendizagem (BERNARDES et al., 2008). No artigo de Ghasempour et al. (2009) também encontramos a temática 
dos telescópios, mas a partir de uma abordagem histórica acerca da instrumentação óptica avançada usada nas observações astronômicas.

Enquanto os livros-texto, mesmo de ensino superior, costumam tratar apenas de aplicações de espelhos esféricos, são fartas as discussões envolvendo geometrias não esféricas na literatura acadêmica. Hare (2007), por exemplo, apresenta sugestões de projetos de aquecedores solares baseados em espelhos parabólicos. As construções indicadas são de baixo custo e pequeno grau de dificuldade, envolvendo placas de madeira e superfícies refletoras que possam ser curvadas no formato parabólico desejado, tais como espelhos plásticos, pedaços de um espelho plano quebrado ou papel alumínio. Paula et al. (2007) também apresenta uma alternativa barata para a construção de espelhos parabólicos que possam vir a ser usados para fins didáticos, tais como a construção de telescópios.

A parábola é uma das quatro curvas cônicas (as outras são o círculo, a hipérbole e a elipse). Este nome é dado pela possibilidade de se obter uma curva com esse formato a partir de uma seção adequada de um cone. Castaño e Hawkins (2011) lidam de forma algébrica para encontrar uma equação que relacione a posição da imagem de um objeto disposto à frente de um espelho cuja curvatura seja uma cônica arbitrária. Os autores confirmam que a superfície parabólica é a única que não apresenta aberração, ou seja, uma imagem pontual única é conjugada para um objeto também pontual, e mesmo essa situação só é conseguida para objetos infinitamente distantes. Essa conclusão dos autores justifica a necessidade de adoção das condições de aproximação de Gauss na abordagem dos espelhos esféricos.

Bruce (2006) também desenvolve uma abordagem teórica da reflexão e da refração em cônicas, mas usando a notação matricial para a óptica geométrica, a qual é incomum mesmo em cursos de graduação, e se restringindo às superfícies elípticas e hiperbólicas. $\mathrm{O}$ autor aplica esse tratamento algébrico na discussão de um telescópio idealizado (mas não construído) por Descartes. Pena e Leitão (2012), por sua vez, tomam o caminho oposto e optam pela simplificação dos cálculos algébricos, mostrando por argumentos geométricos simples as condições que levam um espelho esférico a se comportar como um espelho parabólico: quando os raios paraxiais menos afastados do eixo principal do espelho esférico formam ângulos de incidência relativamente pequenos, há uma concentração destes raios próxima ao plano focal de um espelho parabólico, com um aumento da nitidez da imagem. O processo geométrico de construção desenvolvido pelos autores permite demonstrar para os estudantes que as condições de Gauss não têm um caráter de postulado, emergindo naturalmente das aproximações geométricas.

Apesar das superfícies parabólicas não apresentarem aberrações para objetos distantes, esse fato não se verifica para objetos mais próximos ou fora do eixo principal. Um convincente exemplo é apresentado por Coullet e Filippi (2013), que se inspiram em um problema histórico sobre a multiplicidade de imagens em espelhos parabólicos, o qual foi resolvido por Alhazen no século XI. Usando um espelho de grandes dimensões nesse formato, são produzidas até três imagens de uma pessoa que se poste à frente do mesmo. Mihas (2002) também se apoia nos trabalhos de Alhazen, fornecendo detalhes históricos das investigações que esse autor conduziu 
sobre a reflexão na superfície da Lua, os espelhos compostos e o problema dos pontos de uma superfície onde a reflexão é possível.

Os estudos de Alhazen também são a fonte primária do trabalho de Van Beveren et al. (2006), que descrevem as propriedades da reflexão em espelhos esféricos convexos que Alhazen não poderia conceber em seu tempo: as bolinhas espelhadas que adornam as árvores de Natal. A aparente simplicidade do objeto de estudo é ilusória, pois a determinação da posição da imagem em um espelho como esse só é possível através de uma equação biquadrática, a qual permite conexões com a construção de telescópios refletores em que a aberração seja minimizada. A preocupação dos autores com um tema tão cotidiano se justifica, pois o tratamento de espelhos convexos em livros didáticos de ensino médio é acrítico, daí a vertente pedagógica usada no desenvolvimento do artigo. Um diálogo pode ser estabelecido entre esse trabalho e o artigo de Bongiovanni et al. (2000), o qual se dedica às imagens produzidas por reflexão e refração em "bolhas", tais como aquelas produzidas com água e sabão.

Em sua explanação sobre a multiplicidade de imagens em espelhos parabólicos, Coullet e Filippi (2013) trabalham também com a cáustica, uma aberração óptica muito comum no cotidiano. A cáustica (Fig. 4) é a curva onde raios de luz paralelos incidentes em um espelho côncavo são projetados. Discussões teóricas sobre a cáustica e outras aberrações ópticas estão presentes no trabalho de Avendaño-Alejo et al. (2010), no qual é estudada a curva cáustica em um espelho côncavo, causada pelas múltiplas reflexões da luz emitida por uma fonte puntiforme. O artigo de Escobar et al. (2008) também trabalha com a cáustica e outras aberrações ópticas, mas de forma experimental, a fim de demonstrar as aberrações esféricas e os padrões de desfoque de imagens em cursos introdutórios de óptica universitária.

$\mathrm{Na}$ literatura revisada, entretanto, foi mais frequente a presença de discussões qualitativas sobre esse fenômeno, como a conduzida por Catelli e Vicenzi (2004), que observam a cáustica na luz refletida pela face cilíndrica côncava de uma xícara, enquanto Ferraro (1996) a percebe em anéis. Por sua vez, Vollmer e Möllmann (2012) a correlacionam com as zonas de aquecimento produzidas por edifícios de fachadas côncavas, os quais são recobertos por janelas refletoras. A formação da cáustica de reflexão em objetos tão cotidianos e diversos como xícaras, anéis e edifícios, evidencia a importância do fenômeno e fornece argumentos para refutar a sua exclusão dos livros de ensino médio. 


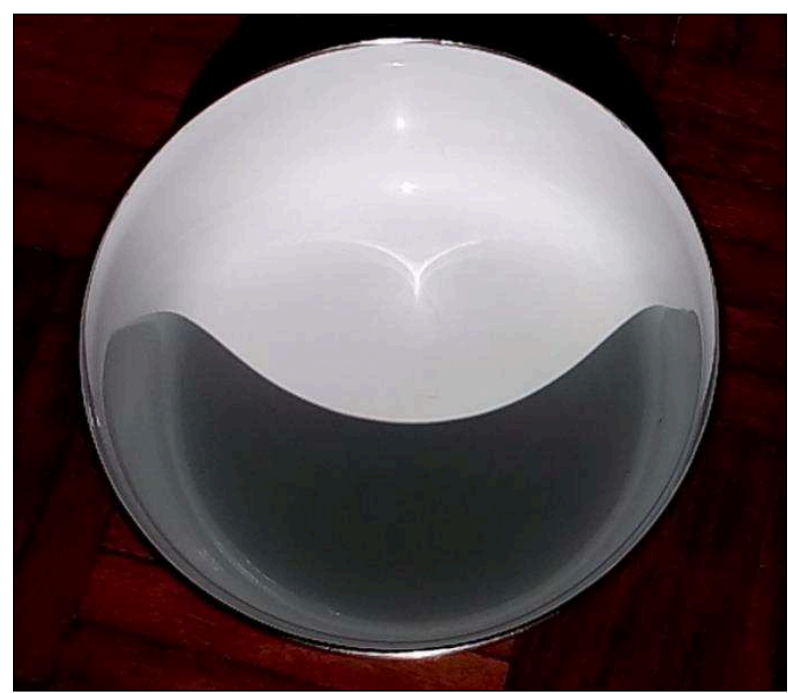

Fig. 4 - Cáustica produzida pela reflexão da luz na superfície côncava de um recipiente cilíndrico.

Espelhos elípticos possuem dois focos, e a luz emitida por uma fonte disposta em um desses pontos, ao se refletir no espelho, irá convergir no segundo. Há diversas formas de provar algebricamente essa propriedade. A forma tradicional envolve o princípio geométrico da igualdade entre os ângulos de incidência e reflexão, mas Sztrajman e Rela (2003) obtém esse resultado a partir da conservação de energia em um sistema mecânico de mesma geometria, enquanto Criado e Alamo (2004) fazem considerações de ordem cinemática para essa demonstração, expandindo sua discussão para as outras cônicas.

Espelhos parabólicos também podem ser obtidos de forma inusitada, a partir de um líquido em rotação. Se um líquido é agitado com uma colher em movimentos circulares, observa-se uma curvatura na superfície: um paraboloide de revolução. Graumann e Laue (1998) propõem um aparato possível de ser reproduzido no ensino médio, usando um líquido em rotação e um inclinômetro, sugerindo diversas atividades experimentais que podem ser realizadas com a montagem. Chandler (2001) dispensa o próprio espelho para explicar o comportamento dos espelhos parabólicos, preferindo apresentar uma atividade de construção de um modelo desse formato de superfície usando dobraduras em papel. Segundo o autor, as propriedades refletivas da parábola, tais como a localização do foco, emergem naturalmente da atividade concreta, a qual pode também ser generalizada para elipses e hipérboles.

Espelhos que não tenham o formato de curvas cônicas também estão presentes na literatura. Deweerd e Hill (2006) discutem as intrigantes propriedades ópticas do espelho helicoidal, um popular elemento decorativo em jardins, além das possibilidades de exploração pedagógica dos mesmos. Estes mesmos autores (DEWEERD e HILL, 2005), em artigo anterior, haviam discutido de forma teórica as características das imagens formadas em espelhos cilíndricos côncavos e convexos. Já o artigo de Caussat et al. (2006) recomenda o uso de uma superfície cilíndrica côncava, obtida com uma chapa metálica curvada nesse formato, para a projeção de uma pseudoimagem, conceito inexistente em livros didáticos. 
Entre tantas propostas, foi motivo de estranheza a carência de propostas interdisciplinares. O trabalho de Vollmer e Möllmann (2012) permite um diálogo entre a arquitetura e a óptica, mas se revelou uma exceção nesse tópico. Outra louvável ressalva é o artigo de Colicchia et al. (2009), que modela o olho das vieiras (um molusco conhecido na gastronomia como uma fina iguaria) a partir de um espelho côncavo. A formação da imagem nos olhos desses animais se assemelha ao mecanismo óptico dos telescópios newtonianos. Os autores apresentam uma sugestão para a construção de um modelo desse olho, a fim de permitir que o ensino dos tópicos da física se realize em um contexto biológico, o qual costuma gerar interesse entre os estudantes.

\section{III.8 Associações de espelhos}

Estão presentes neste item as pesquisas que utilizaram mais de um espelho para suas análises. Enfatiza-se que alguns artigos contemplando associações - e.g. Featonby (2007) - foram incluídos em outros tópicos por não se concentrarem na discussão sobre a associação em si, abordando outros temas (como as propriedades das imagens reais, no caso citado).

Associações de espelhos se adequam ao desenvolvimento de experimentos didáticos, pois a multiplicidade de imagens exige abordagens mais elaboradas, mobilizando diversas habilidades mentais dos estudantes. Assim, a maior parte dos artigos desse item são propostas de atividades experimentais. Há exceções: Silva (2012), por exemplo, desenvolve um trabalho exclusivamente algébrico sobre diversas associações de espelhos esféricos dispostos frente a frente, e Moreno et al. (2010) analisam ressonadores compostos de dois espelhos a partir dos preceitos ópticos de Fourier. O primeiro artigo, embora literal, é acessível ao ensino médio, enquanto o segundo se adequa apenas a estudantes universitários, conforme recomendação dos próprios autores. Já o artigo de Evans (1996) apresenta as dificuldades conceituais que os estudantes apresentam no traçado de raios entre espelhos planos associados em ângulo. Não há uma sugestão de experimento per se no artigo, mas a descrição da atividade permite caracterizá-la como um experimento de "lápis e papel".

A montagem experimental de Quéré e Martin (2010) ofereceu desafios para sua classificação, pois o artigo trabalha com feixes laser de alta energia, os quais criam feixes de plasmas, que por sua vez são refletidos por sistemas análogos a associações de espelhos. O artigo não se dedica exatamente à reflexão luminosa, mas devido à analogia citada, decidimos por sua inclusão nesse item.

A aparelhagem comercial conhecida como Mirage 3D ou mirascópio compreende uma associação de dois espelhos parabólicos frente a frente (Fig. 5). Ao se dispor um pequeno objeto no vértice de um dos espelhos, é formada uma imagem real próxima ao vértice do segundo, sem a necessidade de projeção. Riveros e Rosenberger (2012) discutem esse "truque mágico" em seu artigo, enquanto Silva e Laburú (2015) apresentam uma alternativa de baixo custo ao experimento comercializado, feita com uma simples lâmpada incandescente. Esses autores abordam ainda a montagem simplificada de forma quantitativa, a partir da coleta de dados numéricos 
experimentais, ao contrário do texto anterior, no qual o aparato é trabalhado somente por vias conceituais e geométricas.

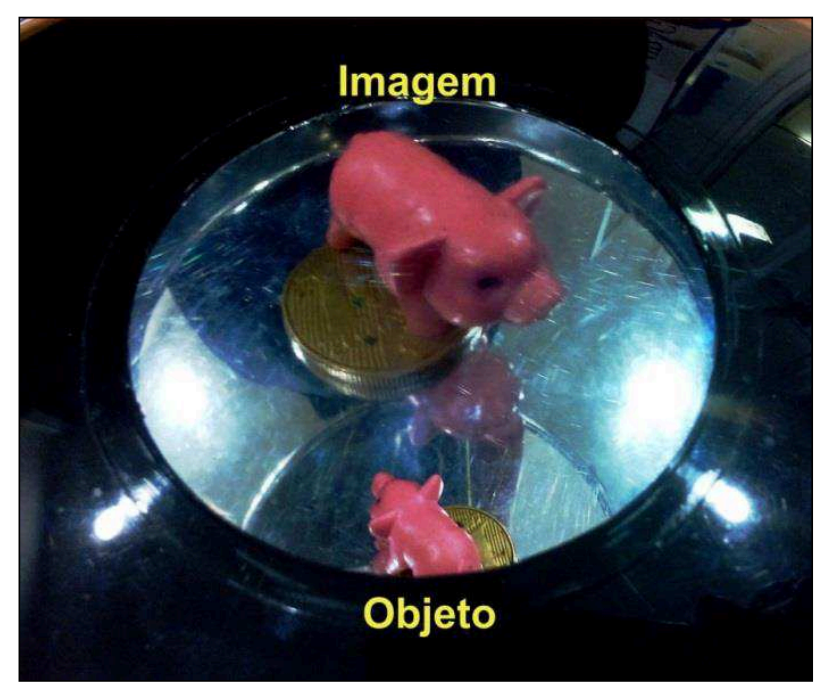

Fig. 5 - Imagem real formada em um mirascópio.

Edifícios com fachadas espelhadas podem ser modelados como espelhos de diferentes formatos. Esse é o tema de Ribeiro (2015b), que representa os prédios da Procuradoria Geral da República, em Brasília, como uma associação de espelhos cilíndricos, sugerindo diversas atividades experimentais que podem ser feitas com um modelo em escala reduzida (duas lixeiras cromadas), mostrando um possível diálogo entre as linguagens da arquitetura e da física.

Instrumentos ópticos diversos utilizam associações de espelhos planos em sua configuração. Esse é o caso dos caleidoscópios tradicionais, onde imagens surreais são observadas devido às múltiplas reflexões em espelhos planos. Estes espelhos formam a face de um prisma, em geral de formato triangular. Greenslade Jr. (2009) descreve como a utilização de grandes espelhos para a sua construção pode trazer vantagens didáticas. O periscópio de submarinos é outro instrumento óptico que utiliza espelhos planos associados, levando Amann (1996) a discutir os vários posicionamentos que tais superfícies refletoras poderiam assumir nesse instrumento. Rovšek (2010), por sua vez, apresenta uma sugestão de associação de três espelhos planos perpendiculares entre si para explicar os princípios físicos do olho-de-gato, popular elemento de sinalização em estradas de rodagem. Hologramas também podem ser produzidos a partir de sistemas de dois espelhos (VANNONI et al., 2007).

Dois espelhos planos paralelos ideais formariam um número infinito de imagens (em teoria), as quais seriam percebidas por um observador como um "túnel virtual". Na prática, como os espelhos cotidianos não possuem refletância total para todas as frequências, as múltiplas reflexões terminam por mostrar cores com tom esverdeado para as imagens geradas por um maior número de reflexões, evidenciando a cor dos espelhos, como percebido por Lee e Hernández-Andrés (2004). O caráter das infinitas imagens produzido por dois espelhos planos paralelos também é discutido por Fadeev (2015), em uma atividade didática produzida a partir 
de uma cena do filme Inception (no Brasil, A Origem), na qual são conjugadas múltiplas imagens do personagem vivido por Leonardo di Caprio.

Dois ou mais espelhos em ângulo fornecem imagens bastante diferenciadas, dependendo do arranjo entre os mesmos. Se objetos extensos forem utilizados, imagens excêntricas podem ser conseguidas nessas montagens, tais como ciclopes (RIBEIRO, 2014) e triclopes (RIBEIRO, 2015a). Se um maior número de espelhos for utilizado, a complexidade das imagens produzidas pode exigir análises diferenciadas, como o método dos espelhos virtuais (GREENSLADE JR, 2010).

\section{III.9 Polarização}

Ondas eletromagnéticas como a luz podem apresentar o fenômeno da polarização, por terem vibração transversal. Há três variantes desse fenômeno: polarização plana (o plano de vibração do campo elétrico é perpendicular à direção de propagação da onda), polarização circular (o campo elétrico se mantém perpendicular à direção de propagação, mas apresenta uma rotação fixa em sentido horário ou anti-horário) ou polarização elíptica (idem à anterior, mas com a rotação em formato elíptico e não circular).

A luz pode ser polarizada por diversos processos ópticos, tais como a absorção, a transmissão, o espalhamento e a reflexão, razão pela qual alguns artigos constantes nessa revisão foram incluídos nesse tópico, por terem suas linhas de investigação centradas na relação entre reflexão e polarização.

O trabalho de Brody et al. (2013) se dedica à reflexão de um feixe cônico de luz polarizada, e apresenta uma combinação de teoria geométrica densa, simulação computacional e demonstração experimental surpreendente. Tal combinação é defendida pelos autores por prover os estudantes de habilidades úteis, tal como a atenção aos detalhes da teoria, o treinamento prático com equipamentos laboratoriais e o exercício de técnicas de simulação.

Ouseph (2002) também apresenta uma combinação de teoria e sugestões experimentais, mas com menor rigor algébrico, razão pela qual consideramos seu artigo como uma adequada introdução às relações entre os fenômenos da reflexão e da polarização, em especial no tocante à variação do nível de polarização com o ângulo de incidência, mesmo para estudantes de ensino médio. Percebe-se, entretanto, que o artigo citado tem sua origem em um tratamento prévio conduzido pelo grupo de estudos do pesquisador (OUSEPH, et al., 2001), no qual o tratamento matemático equivale ao exposto por Brody et al. (2013), sendo adequado apenas para o nível superior. Consideramos interessante a percepção do pesquisador de que seu trabalho poderia ser simplificado, em uma tentativa de transposição didática para plateias formadas por não especialistas.

O estudo da polarização remete aos trabalhos de Malus e Brewster no século XIX, o que pode levar à crença errônea de um campo de estudo estático desde então. Ao contrário, McCall e Hodgkinson (2009), em seu artigo, rediscutem a conjectura de Brewster sobre a igualdade entre as intensidades da luz refletida e transmitida para um ângulo particular, nomeado 
ângulo de Brewster. Os autores argumentam que, para certos elementos polarizadores lineares, essa igualdade é verificada para qualquer comprimento de onda (luz natural) e qualquer ângulo de incidência, e fornecem evidências experimentais como suporte da argumentação, revitalizando o campo de pesquisa na área.

As propriedades da luz refletida polarizada, entretanto, não necessitam de aparatos tecnológicos sofisticados para serem determinadas. Essa é a defesa de Monzón e Sánchez-Soto (2002), que apresentam um método geométrico simples e intuitivo para a caracterização da polarização da luz transmitida e refletida por um meio transparente. Segundo os autores, o próprio ângulo de Brewster emerge de forma natural do método de trabalho, feito com "régua e compasso".

Polarizadores têm destaque em diversas tecnologias que passaram a permear o nosso cotidiano nas últimas décadas, tais como televisões de cristal líquido (liquid crystal display, ou LCD) ou em óculos utilizados no cinema tridimensional (3D). Apesar disso, esta revisão revelou um único artigo dedicado à conexão de tais tecnologias com os fenômenos refletivos. Ribeiro e Verdeaux (2012b) apresentam um experimento simples, feito com óculos polarizadores, usados em exibições de filmes 3D. Se uma pessoa se olhar no espelho enquanto usa esses óculos e fechar um dos olhos, a lente que recobre o olho oposto (aberto) parecerá negra, impedindo a visualização da imagem desse olho, enquanto a imagem refletida do olho fechado continuará sendo observada. O fenômeno é simples, lúdico e intrigante, e adequado à apresentação no ensino médio, e sua elucidação exige a compreensão da reflexão de luz polarizada.

\section{III.10 Espelhos relativísticos}

Durante a etapa de seleção dos artigos, já possuíamos expectativas sobre o aparecimento de certos temas, tais como relatos de pesquisas dedicadas a espelhos curvos ou associações de espelhos, por nossa experiência em pesquisas na área. Entretanto, emergiu da base de dados consultada a necessidade de reservar um espaço a trabalhos que lidam com a óptica relativística, um tópico de classificação que se revelou inesperado para nós, mas não por isso menos interessante. Foi possível constatar a carência de propostas didáticas voltadas para o ensino médio que relacionem os temas da óptica e da relatividade, abrindo possibilidades para novas pesquisas.

Os trabalhos incluídos nessa categoria são teóricos por natureza, dadas as dificuldades tecnológicas inerentes, e levam em conta os pressupostos da teoria da relatividade desenvolvida por Einstein no início do século XX, seu tratamento matemático peculiar (as transformações de Lorenz) e suas consequências não intuitivas (dilatação do tempo, contração do comprimento, efeito Doppler relativístico, entre outros).

O postulado principal da relatividade é a constância da velocidade da luz no vácuo, a qual é independente do estado de movimento do observador. Uma explanação detalhada sobre as relações entre a óptica e a teoria da relatividade foge do escopo dessa revisão; entretanto, acreditamos que o artigo de Gjurchinovski e Skeparovski (2008) seria adequado como uma 
introdução ao tema. Os autores trabalham com a reflexão de luz de um espelho plano em movimento retilíneo uniforme, um problema investigado pela primeira vez pelo próprio Einstein, a partir das transformações de Lorentz, em um notório artigo de 1905. Assim como fez para os conceitos newtonianos de espaço e tempo absolutos, Einstein mostrou as limitações da óptica geométrica clássica, provando que a igualdade entre os ângulos de incidência e reflexão da luz não é verificada. Gjurchinovski e Skeparovski (2008) desenvolvem um tratamento alternativo, procurando manter o tratamento matemático no nível do ensino médio e assim possibilitando sua abordagem em turmas dessa fase. Tal violação da igualdade entre os ângulos na reflexão é desenvolvida de forma independente por Galli e Amiri (2012), que introduzem um princípio geral para determinar a relação entre esses dois ângulos, e o aplicam para diferentes geometrias, indo além dos espelhos planos.

Um dos autores do texto recomendado como introdutório desenvolve esse ideário com maior rigor matemático em artigos posteriores, correlacionando a reflexão da luz em um espelho relativístico com o princípio de Fermat (GJURCHINOVSKI, 2004a) e demonstrando que o espelho em movimento uniforme sofreria contração do seu comprimento na direção do seu movimento, de acordo com os postulados da relatividade (GJURCHINOVSKI, 2004b). O princípio de Fermat também é discutido por Berenguer (2011), em um tratamento generalista, o qual trata a reflexão e a refração da luz em uma geometria não euclidiana, um dos pilares matemáticos da relatividade.

Gjurchinovski (2013) apresenta ainda outro texto introdutório aos efeitos observados quando a luz é refletida por um espelho em movimento uniforme, mas usando o modelo corpuscular (fóton) e as leis de conservação da energia e momento linear. Para o autor, essa abordagem centrada em conceitos da dinâmica clássica facilita o entendimento por parte dos estudantes, por não exigir conhecimentos prévios da teoria da relatividade, sendo adequada em cursos introdutórios de óptica. Outro trabalho também lida com as trocas de energia entre os fótons e o espelho relativístico (GOEDECKE et al., 2012), mostrando que o pulso refletido tem maior energia e menor comprimento de onda que o incidente, conforme o espelho se aproxima da velocidade da luz (esse fenômeno é um exemplo do efeito Doppler relativístico).

Movimentos diversos dos citados acima são discutidos em outros artigos: Van Meter et al. (2001) trabalha com espelhos em movimento uniformemente acelerado, enquanto Rothenstein (1995) se dedica às trajetórias circulares. Laing (1997) vai além, e discute os "ecos luminosos", um fenômeno pouco discutido, o qual ocorre com a luz emitida por algumas estrelas supernovas que possuem movimentos aparentes com velocidades superiores à da luz, chamados superluminais ${ }^{8}$. Esses "ecos" ocorrem devido à reflexão da luz advinda desses corpos celestes em diferentes nuvens de poeira interestelar.

\footnotetext{
${ }^{8}$ Frisamos o termo aparente: nesse contexto, os corpos superluminais não são mais rápidos que a luz, pois isso violaria o postulado fundamental da relatividade.
} 


\section{Conclusões e perspectivas}

Alguns riscos são inerentes à confecção de qualquer revisão bibliográfica. Entre outros, existe a chance de artigos escaparem ao "radar" do revisor; a divisão em categorias pode se revelar artificial ou incompleta; a abrangência geográfica e temporal da revisão pode ser limitada. Assim, é inevitável admitir a possibilidade de incompletude desse trabalho, quiçá de qualquer revisão, devido a tais riscos. Entretanto, acreditamos que a variedade de revistas acadêmicas nacionais e internacionais, publicadas em quatro línguas diferentes em um período de duas décadas permite diminuir os riscos de abrangência da revisão. A metodologia utilizada (adaptativa para cada portal eletrônico) também permitiu incluir artigos que teriam escapado ao nosso olhar em uma pesquisa mais superficial, baseada apenas em marcadores. Por fim, estabelecemos como categorias de classificação os subtemas já tradicionais no estudo da reflexão, sedimentados em livros didáticos (acrescidos de outros mais incomuns), a fim de buscar uma maior naturalidade na categorização.

Nossa pesquisa revelou não existirem na literatura consultada sugestões de tratamento didático elaboradas por autores brasileiros para os espelhos relativísticos. Em especial, essa ausência de propostas para o ensino médio nos preocupa. O princípio fundamental da reflexão na óptica clássica (igualdade entre os ângulos de incidência e reflexão) é violado em espelhos relativísticos, um fato que poderia vir a se mostrar interessante para estudantes da educação básica, mostrando uma aplicação comumente não discutida da teoria da relatividade de Einstein. O princípio fundamental da relatividade é a constância da velocidade da luz no vácuo em todos os referenciais, mas aplicações desse princípio são voltadas para a cinemática nos livros didáticos de ensino médio, e não para a óptica.

A mesma ausência relativa de pesquisas nacionais ocorre também para os subtemas da refletância e da velocidade da luz. Poder-se-ia dizer que a relação entre reflexão e polarização é pouco explorada, pois o único artigo acerca dessa relação publicado por autores brasileiros que encontramos na literatura é de nossa própria autoria (RIBEIRO; VERDEAUX, 2012b), fato que consideramos preocupante: os filtros polarizadores utilizados em fotografia para eliminar os reflexos em superfícies de vidro são uma aplicação óbvia dessa relação. Assim, consideramos os subtemas citados nesse parágrafo e no anterior como férteis searas de pesquisa, dada a carência que nossa revisão apontou.

A leitura da Fig. 2 aponta para uma grande concentração de trabalhos em aplicações de espelhos curvos e planos. A relevância desses subtemas é notória e, por si só, explica tal predominância, mas admitimos que uma divisão do subtema dos espelhos curvos - por exemplo, "espelhos esféricos" e "espelhos não esféricos" - poderia ter sido conduzida, relativizando a predominância do subtema "espelhos curvos". Entretanto, como já frisamos ao longo do texto, tal divisão provavelmente levaria à dupla categorização de artigos, obrigando a mudanças na metodologia de pesquisa. 
A revisão da literatura permitiu ainda estabelecer como manifesta a valorização do uso de materiais cotidianos em pesquisas experimentais por parte dos pesquisadores, principalmente em artigos voltados para o tratamento da óptica no ensino médio. Embora tal conclusão não se apresente como novidade no ensino de ciências, ainda assim cabe ressaltá-la, pois a variedade de materiais utilizados pode impressionar: entre outros, encontram-se sugestões de aprendizagem do tema da reflexão luminosa a partir de espelhos de banheiro comuns (ROEDER, 2012), lâminas plásticas de retroprojetores (BERRY; KLEIN, 1997), poças de água da chuva (ALLOCO, 1999), xícaras de café ou chá (ZANARDI; MURAMATSU, 2011; DEWEERD; HILL, 2005), CDs (MOHAMMADPOUR, 2008; MANSELL, 2007; GLUCK, 2002), blocos de parafina e papel alumínio (TANTILLO, 2008), revestimentos metálicos em elevadores (GROSSMAN, 2014), colheres (BALTA; ERYILMAZ, 2011), azulejos decorativos (PROVIDÊNCIA; PROVIDÊNCIA, 2014), discos de vinil (GOUGH, 2006), medalhões de latão (MILLS, 2011), espelhos retrovisores de automóveis (LIBERTUN, 2003), taças de vinho (RIBEIRO, 2013), lâmpadas incandescentes (CATELLI; REIS, 2004), bolhas de água e sabão (BONGIOVANNI et al., 2000), bolas de árvores de Natal (BEVEREN et al., 2006), espelhos decorativos de jardim (DEWEERD; HILL, 2006), óculos de cinema tridimensional (RIBEIRO e VERDEAUX, 2012b) e caleidoscópios (GREENSLADE JR., 2009). Essa diversidade aponta para uma grande facilidade de se pesquisar os fenômenos refletivos, levando à produção continuada de literatura acadêmica acerca do tema, como essa revisão demonstra, em particular na Fig.1. A leitura desse gráfico de barras permite inferir que a pesquisa acerca da reflexão luminosa não só é contínua, mas também tem se intensificado na última década.

Lamentamos que a celebração do Ano Internacional da Luz (2015), ao contrário do possivelmente esperado pela comunidade científica, não ter impulsionado a produção de um maior número de artigos sobre reflexão luminosa. Apesar disso, o número de publicações em 2015 (dez artigos) ficou acima da média para o período pesquisado (entre sete e oito artigos anuais). Entretanto, a produção sobre o tema da reflexão luminosa nos últimos dez anos foi mais intensa, e se apenas essa última década for levada em conta, o número de artigos publicados em 2015 se apresenta apenas na média, o que encaramos como uma decepção em um ano que deveria celebrar a luz como objeto de pesquisa. Apesar dessas ressalvas, acreditamos ter havido uma mudança positiva nas temáticas a que os pesquisadores se dedicaram durante o Ano Internacional da Luz. Entre elas, destacamos a busca pela correlação da história da óptica com o desenvolvimento dos seus princípios, e.g. Moura e Boss (2015), Martins e Silva (2015) e Souza et al. (2015).

\section{Referências}

ADIE, G. Using the laser pointer as a demonstration tool. Physics Education, v. 32, p. 190191, 1997. 
AGUIAR, C. Óptica e geometria dinâmica. Revista Brasileira de Ensino de Física, v. 31, n. 3, p. 3302.1-3302.5, 2009.

ALLOCCO, M. Puddle of light. The Physics Teacher, v. 37, n. 8, p. 468, 1999.

ALMEIDA, W.; LUZ, F.; SILVA, J.; SILVA, S.; BRINATTI, A. Espelhos esféricos confeccionados com materiais acessíveis para demonstração de formação de imagens em sala de aula. Caderno Brasileiro de Ensino de Física, v. 30, n. 2, p. 396-408, 2013.

AMANN, G. An old periscope with a new 'twist'. The Physics Teacher, v. 34, n. 7, p. 408409, 1996.

ANJOS, I. Física para o ensino médio. 1. ed. São Paulo, IBEP, 2005. p. 259-280. v. único.

AVENDAÑO-ALEJO, M.; CASTAÑEDA, L.; MORENO, I. Caustics and wavefronts by multiple reflections in a circular surface. American Journal of Physics, v. 78, n. 11, p. 11951198, 2010.

BAIRD, W. Helping the Moon take a selfie. Physics Education, v. 49, n. 5, p. 486, 2014.

BALTA, N.; ERYILMAZ, A. Upside-down image in a spoon. Physics Education, v. 46, n. 4, p. 380-382, 2011.

BAPAT, M. Using ethnic art to emphasize laws of reflection. The Physics Teacher, v. 47, n. 8, p. 542-543, 2009.

BARTLETT, A. Pinhole mirror. The Physics Teacher, v. 34, n.8, p. 479, 1996.

BERENGUER, R. Óptica relativista y geometría no euclídea. Latin-American Journal of Physics Education, v. 5, n. 3, p. 548-555, 2011.

BERNAL, L.; BILBAO, L. Optical Doppler shift measurement using a rotating mirror. American Journal of Physics, v. 75, n. 3, p. 216-219, 2007.

BERNARDES, T.; BARBOSA, R.; BATAGIN, A.; IACHEL, G.; PINHEIRO, M.; SCALVI, R. Abordando o ensino de Óptica através da construção de telescópios. Revista Brasileira de Ensino de Física, v. 28, n. 3, p. 391-396, 2006.

BERNARDES, T.; IACHEL, G.; SCALVI, R. Metodologias para o ensino de Astronomia e Física através da construção de telescópios. Caderno Brasileiro de Ensino de Física, v. 25, n. 1, p. 103-117, 2008. Metodologias para o ensino de astronomia e Física através da construção de telescópios. Caderno Brasileiro de Ensino de Física, v. 25, n. 1, p. 103 $117,2008$. 
BERRY, M. V. Oriental magic mirrors and the Laplacian image. European Journal of Physics, n. 1, p. 109-118, 2005.

BERRY, M.; KLEIN, S. Transparent mirrors: rays, waves and localization. European Journal of Physics, v. 18, n. 3, p. 222-228, 1997.

BHATTACHARJEE, P. The generalized vectorial laws of reflection and refraction. European Journal of Physics, v. 26, n. 5, p. 901-912, 2005.

BONGIOVANNI, C.; DOMINGUEZ, A.; CHEVAILlIER, J. Understanding images of bubbles. European Journal of Physics, v. 21, p. 561-570, 2000.

BONJORNO, J.; BONJORNO, R.; BONJORNO, V.; RAMOS, C.; ALVES, L. Física: termologia, óptica e ondulatória. 1. ed. São Paulo, FTD, 2010. p.222-226. v. 2.

BOULOMYTIS, V.; GARCIA, C.; SILVA, F.; TRABAQUINI, K.; CORRÊA, S. Proposta metodológica para o estudo da reflectância e da transmitância de uma superfície lambertiana no âmbito do sensoriamento remoto. Latin-American Journal of Physics Education, v. 5, n. 2, p. 461-466, 2011.

BRAGA, G. Relações bibliométricas entre a frente de pesquisa (research front) e revisões da literatura: estudo aplicado à Ciência da Informação. Ciência da Informação, v. 2, n. 1, p. 926, 1973.

BRODY, J.; WEISS, D.; BERLAND, K. Reflection of a polarized light cone. American Journal of Physics, v. 81, n. 1, p. 24-27, 2013.

BRUCE, I. ABCD transfer matrices and paraxial ray tracing for elliptic and hyperbolic lenses and mirrors. European Journal of Physics, v. 27, n. 2, p. 393-406, 2006.

BUENO, B. Editorial. Educação e Pesquisa, v. 27, n. 1, p. 7-8, 2001.

CALVO, M. En el Centenario de la Real Sociedad Española de Física: una aproximación a los comienzos de la Óptica en España en el siglo XX. Revista Española de Física, v. 17, n.1, p. 10-14, 2011.

CAMARGO, E.; NARDI, R.; MACIEL FILHO, P.; ALMEIDA, D. Como ensinar óptica para alunos cegos e com baixa visão. Física na Escola, v. 9, n. 1, p. 20-25, 2008.

CARLSON, J. The signaling mirror: a life-saving application of reflection and refraction. The Physics Teacher, v. 52, n. 6, p. 374-375, 2014.

CASTAÑO, D.; HAWKINS, L. Conicoid mirrors. European Journal of Physics, v. 32, n. 2, p. 399-405, 2011. 
CATELLI, F. LAZZARI, F. Interferência da Luz: uma versão simplificada do espelho de Lloyd. Física na Escola, v. 5, n. 2, p. 20-22, 2004.

CATELLI, F.; REIS, C. Demonstre em aula: imagens dentro de lâmpadas. Caderno Brasileiro de Ensino de Física, v. 21, n. 1, p. 115-119, 2004.

CATELLI, F.; VICENZI, S. Óptica geométrica no café da manhã. Caderno Brasileiro de Ensino de Física, v. 21, n. 3, p. 392-400, 2004.

CAUSSAT, M.; RABAL, H.; MURAMATSU, M. The levitating Buddha: constructing a realistic cylindrical mirror pseudo image. The Physics Teacher, v. 44, n. 7, p. 443-444, 2006.

CAVALCANTE, M.; RODRIGUES, E. Uso do "espelho de Lloyd" como método de ensino de óptica no Ensino Médio. Revista Brasileira de Ensino de Física v. 34, n. 4, p. 4310.1-4310.4, 2012.

CEPIC, M. Does a virtual image cast a shadow? Physics Education, v. 41, n. 4, p. 295-297, 2006.

CHANDLER, D. Understanding parabolic reflectors through paper folding. The Physics Teacher, v. 39, n. 1, p. 24-25, 2001.

CHIRINO, S.; RODRÍGUEZ, N.; RODRÍGUEZ, G. Aprendizaje de contenidos de óptica geométrica utilizando software didáctico. Revista de Enseñanza de la Física, v. 27, n. 2, p. 37 44, 2015.

COLICCHIA, G.; WALTNER, C.; HOPF, M.; WIESNER, H. The scallop's eye - a concave mirror in the context of biology. Physics Education, v. 44, n. 2, p. 75-179, 2009.

COULLET, P.; FILIPPI, J. Des corps flottants aux miroirs déformants-Une cité de la géométrie à l’Université de Nice Sophia Antipolis. Reflets de la Physique, n. 32, p. 34-37, 2013.

COVARRUBIAS, H. Successive reflections of a light beam on a pair of plane mirrors. American Journal of Physics, v. 58, n. 6, p. 565-567, 1990.

CRIADO, C.; ALAMO, N. Optical properties of the conics derived from an elementary kinematic consideration. The Physics Teacher, v. 42, n. 5, p. 272-273, 2004.

DAFFRON, J.; GREENSLADE JR, T. Modern kaleidophones. The Physics Teacher, v. 53, n. 7, p. 407-408, 2015.

DE JESUS, V.; SASAKI, D. Utilização do conceito de aumento angular para interpretar imagens observadas em espelhos esféricos côncavos. Revista Brasileira de Ensino de Física, v. 35, n.1, p. 1506.1-1506.7, 2013. 
DE LUCA, R.; FEDULLO, A. Focusing light rays back to the vertex of a reflecting parabolic collector: the equivalent of Dionysius ear effect in optical systems. European Journal of Physics, v. 30, n. 5, p. 935-943, 2009.

DELIZOICOV, D. Pesquisa em ensino de ciências como ciências humanas aplicadas. Caderno Brasileiro de Ensino de Física, v. 21, n. 2, p. 145-175, 2004.

DEWEERD, A.; HILL, S. Optics over a cup of tea: images in concave and convex surfaces. Physics Education, v. 40, n. 1, p. 13-14, 2005. .; Reflection with a twist: the helical mirror. The Physics Teacher, v. 44, n. 8, p. 496-497, 2006.

275-279, 2004. .; The dizzying depths of the cylindrical mirror. The Physics Teacher, v. 43, n. 2, p. 90-92, 2005.

ENNOS, A. Laser speckle experiments for students. Physics Education, v. 31, n. 3, p. 138$142,1996$.

ERB, R. Curved mirrors. Physics Education, v. 30, n. 5, p. 287-288, 1995.

. Designing an improved reflector. Physics Education, v. 32, p. 100-103, 1997.

ESCOBAR, I.; SAAVEDRA, G.; PONS, A.; MARTÍNEZ-CORRAL, M. Simple demonstration of the impact of spherical aberration on optical imaging. European Journal of Physics, v. 29, n. 3, p. 619-627, 2008.

EVANS II, H. Ray tracing with hinged mirrors. The Physics Teacher, v. 34, n. 5, p. 314-315, 1996.

FADEEV, Pavel. Two Mirrors: Infinite Images of DiCaprio. The Physics Teacher, v. 53, n. 8, p. 473-474, 2015.

FAKHRUDDIN, H. Specular reflection from a rough surface. The Physics Teacher, v. 41, n. 4, p. 206-207, 2003.

FEATONBY, D. How to make the 'real image' more real. Physics Education, v. 42, n. 3, p. 126, 2007.

FERRARO, P. What a caustic! The Physics Teacher, v. 34, n. 9, p. 572-573, 1996.

FERREIRA, L.; QUEIROZ, S. Textos de divulgação científica no ensino de ciências: uma revisão. Alexandria: Revista de Educação em Ciência e Tecnologia, v. 5, n. 1, p. 3-31, 2012. 
FIGUEIREDO, N. Da importância dos artigos de revisão da literatura. Revista Brasileira de Biblioteconomia e Documentação, v. 23, n. 1, p. 131-135, 1990.

GALLI, J.; AMIRI, F. A general principle for light reflecting from a uniformly moving mirror: a relativistic treatment. American Journal of Physics, v. 80, n. 8, p. 680-683, 2012.

GARDNER, M. Mirror levitations. The Physics Teacher, v. 37, n. 8, p. 468, 1999.

GHASEMPOUR, A.; MARQUES, P.; GARCIA, J.; LEITE, A. Astrofotónica: instrumentação óptica avançada em astronomia. Gazeta da Física, v. 32, n. 2, p. 2-7, 2009.

GJURCHINOVSKI, A. Einstein's mirror and Fermat's principle of least time. American Journal of Physics, v. 72, n. 10, p. 1325-1327, 2004a.

. Reflection from a moving mirror-a simple derivation using the photon model of light. European Journal of Physics, v. 34, n. 6, p. L1-14, 2013.

Reflection of light from a uniformly moving mirror. American Journal of Physics, v. 72, n. 10, p. 1316-1324, 2004b.

GJURCHINOVSKI, A.; SKEPAROVSKI, A. Einstein's mirror. The Physics Teacher v. 46, n. 7, p. 416-418, 2008.

GLUCK, P. Compact disk optics. The Physics Teacher, v. 40, n. 8, p. 468-469, 2002.

GOEDECKE, G.; TOUSSAINT, V.; COOPER, C. On energy transfers in reflection of light by a moving mirror. American Journal of Physics, v. 80, n. 8, p. 684-687, 2012.

GONZÁLEZ, J.; BRAVO, A.; JUÁREZ, K. Interference of laser light scattered from a “dusty” plane mirror. American Journal of Physics, v. 67, n. 9, p. 839-840, 1999.

GOUGH, W. Stereoscopic effects with a long-playing record. European Journal of Physics, v. 27, n. 2, p. 461-465, 2006.

GRAHAM, R. Real image produced by a concave mirror. The Physics Teacher v. 44, n. 1, p. 186, 2006.

GRAUMAnN, H.; LAUE, H. Concave liquid-mirror experiments. The Physics Teacher, v. 36, n. 1, p. 28-31, 1998.

GREENSLADE JR, T. A quick experiment on reflection from concave mirrors. The Physics Teacher, v. 38, n. 4, p. 206, 2000.

Kaleidoscopes made with big mirrors. The Physics Teacher, v. 47, n. 6, p. 334-

335, 2009.

. Virtual mirrors. The Physics Teacher, v. 48, n. 1, p. 26-27, 2010. 
GROSSMAN, J. Vampire selfie: a curious case of an absent reflection. The Physics Teacher, v. 52, n. 8, p. 458-459, 2014.

GUIMARÃES, O.; PIQUEIRA, J.; CARRON, W. Física 2. 1. ed. São Paulo, Ática, 2013. p. 210-240.

HARE, J. Solar heaters and other parabolic devices. Physics Education, v. 42, n. 3, p. 267270, 2007.

HAWKES, P. Comment on 'The generalized vectorial laws of reflection and refraction' by P R Bhattacharjee. European Journal of Physics, v. 35, n. 6, 2014.

HENDRY, A. A triple rainbow? The Physics Teacher, v. 41, n. 8, p. 460-463, 2003.

HUGHES, S. Catchers of the Light: the forgotten lives of the men and women who first photographed the heavens. 1 ed. ArtDeCiel Publishing, 2012. p. 202-223.

IWANAGAA, M.; VENGURLEKAR, A; HATANO, T.; ISHIHARAB, T. Reciprocal transmittances and reflectances: an elementary proof. American Journal of Physics, v. 75, n. 10, p. 899-902, 2007.

KEEPORTS, D. Reflections from a Fresnel lens. Physics Education, v. 40, n.1, p. 60-66, Janeiro, 2005.

KOKHANOVSKY, A. Optics of turbid slabs. European Journal of Physics, v. 23, n. 1, p. 27 $33,2002$.

KORSUNSKY, B. The star and the imagemaker (M3). The Physics Teacher, v. 43, n. 5, p. 312, 2005.

KRAPAS, S. El tratado sobre la luz de huygens y su transposición didáctica en la enseñanza introductoria de óptica. Revista de Enseñanza de la Física, v. 21, n. 2, p. 49-60, 2011.

KÜÇÜKÖZER, A. Differentiating real and virtual images. Physics Education, v. 46, n. 6, p. 656-658, 2011.

LABURÚ, C. Seleção de experimentos de física no ensino médio: uma investigação a partir da fala de professores. Investigações em Ensino de Ciências, v. 10, n. 2, p. 161-178, 2005.

LAING, R. A. Faster than light: superluminal motion and light echoes. Physics Education, v. 32, n. 1, p. 30-34, 1997.

LEE JR, R.; HERNÁNDEZ-ANDRÉS, J. Virtual tunnels and green glass: the colors of common mirrors. American Journal of Physics, v. 72, n. 1, p. 53-59, 2004.

LIBERTUN, A. Warning! Objects in mirror are closer than they appear. The Physics Teacher, v. 41, n. 1, p. 20-21, 2003. 
LIÑARES, J.; NISTAL, M. A wave-optics approach to paraxial geometrical laws based on continuity at boundaries. European Journal of Physics, v. 32, n. 5, p. 1331-1345, 2011.

LUNAZZI, J.; MAGALHÃES, D.; AMON, M.; TOLEDO, R. La óptica de imágenes en la extensión universitaria de Unicamp. Latin-American Journal of Physics Education, v. 4, n. 2, p. 441-449, 2010.

MAIZTEGUI, A.; CHAMORRO, G.; TISERA, J. Un procedimiento experimental para ubicar imágenes. Caderno Brasileiro de Ensino de Física, v. 15, n. 2, p. 136-163, 1998.

MANSELL, P. Where is the reflection? The Physics Teacher, v. 45, n. 2, p. 119, 2007.

MARTINS, R.; SILVA, A. As pesquisas de Newton sobre a luz. Revista Brasileira de Ensino de Física, v. 37, n. 4, p. 4202.1-4202.32, 2015.

Princípios da óptica geométrica e suas exceções: Heron e a reflexão em espelhos.

Revista Brasileira de Ensino de Física, v. 35, n. 1, p. 1605.1-1605.9, 2013.

MCCALL, M.; HODGKINSON, I. Properties of partially polarized light remitted from lossless polarizing elements. European Journal of Physics, v. 30, n. 4, p. 63-80, 2009.

MIHAS, P. Some historical resources for teaching about curved mirrors. Physics Education, v. 37, n. 4, p. 311-17, 2002.

. The problem of focusing and real images. European Journal of Physics, v. 29, n. 3, p. 539-553, 2008.

MILLS, A. Magic mirrors. Physics Education, v. 46, n. 5, p. 595-598, 2011.

MOHAMmAdPOUR, H. Look Around to Learn Physics. The Physics Teacher, v. 46. n. 3, p. 158-159, 2008.

MOLESINI, G.; VANNONI, M. Light reflection from water surfaces perturbed by falling rain droplets. European Journal of Physics, v. 30, n. 5, p. 1009-1014, 2009.

Light reflection in a pool under falling rain droplets. European Journal of Physics, v. 29, n. 3, p. 403, 2008.

MONZÓN, J.; SÁNCHEZ-SOTO, L. Constructing Fresnel reflection coefficients by ruler and compass. European Journal of Physics, v. 23, p. 255-262, 2002.

MOORE, J.; FLOYD, R. THOMPSON, C. Using billiard balls to explore the concept of virtual images. Physics Education, v. 46, n. 4, p. 382-384, 2011.

MORENO, I.; GARCIA-MARTINEZ, P.; FERREIRA, C. Teaching stable two-mirror resonators through the fractional Fourier transform. European Journal of Physics, v. 31, n. 2, p. 273-284, 2010. 
MORIZOT, O.; SELLÉ, A.; FERRI, S.; GUYOMARC'H, D.; LAUGIER, J.; KNOOP, M. A modern Fizeau experiment for education and outreach purposes. European Journal of Physics, v. 32, n. 1, p. 161-168, 2011.

MOTTER, A. Uma introdução à formulação variacional da óptica geométrica. Revista Brasileira de Ensino de Física, v. 19, n. 2, p. 189-200, 1997.

MOURA, B.; BOSS, S. Thomas Young e o resgate da teoria ondulatória da luz: uma tradução comentada de sua Teoria Sobre Luz e Cores. Revista Brasileira de Ensino de Física, v. 37, n. 4, p. 4203/1-4203/24, 2015.

MOURA, B.; SILVA, C. Newton antecipou o conceito de dualidade onda-partícula? LatinAmerican Journal of Physics Education, v. 2, n. 3, p. 218-227, 2008.

NEWTON, I. Opticks: or, a treatise of the reflections, refractions, inflections and colours of light. 4 ed. William Innys, Londres, 1730. Disponível em: <https://books.google.com.br/books?id=GnAFAAAAQAAJ\&printsec=frontcover\&hl=pt-BR\&source=gbs_ge_summary_r\#v=onepage\&q\&f=false $>$. Acesso em: 30 ago. 2015.

ORTIZ, M.; MONTECINOS, A. How to measure the speed of light at your university with a dinner budget. Revista Brasileira de Ensino de Física, v. 37, n. 1, p. 1502.1-1502.6, 2015.

OSTERMANN, F.; MOREIRA, M. Uma revisão bibliográfica sobre a área de pesquisa "Física Moderna e Contemporânea no Ensino Médio". Investigações em Ensino de Ciências, v. 5, n. 1, p. 23-48, 2000.

OUSEPH, P. Polarization of reflected light. The Physics Teacher, v. 40, n. 7, p. 438-439, 2002.

OUSEPH, P.; DRIVER, K.; CONKLIN, J. Polarization of light by reflection and the Brewster angle. American Journal of Physics, v. 69, n. 11, p. 1166-1168, 2001.

PALEIOV, O.; PUPKO, O.; LIPSON, S. Demonstrating Fermat's principle in optics. Physics Education, v. 46, n. 6, p. 702-704, 2011.

PAULA, L.; RAGGI, P.; ASSIS, A. Uma contribuição à construção de espelhos parabólicos. Caderno Brasileiro de Ensino de Física, v. 24, n. 3, p. 338-352, 2007.

PENA, F.; LEITÃO, V. Quando é que um espelho esférico pode funcionar tão bem como um espelho parabólico? Caderno Brasileiro de Ensino de Física, v. 29, n. 1, p. 180-182, 2012.

PROVIDÊNCIA, C. Mão direita e mão esquerda: qual é a diferença? Gazeta de Física, v. 32, n. 1, p. 42-44, 2009.

PROVIDÊNCIA, C.; PROVIDÊNCIA, P. Que simetrias encontras? Gazeta de Física, v. 37, n. 3, p. 40-42, 2014. 
QUÉRÉ, F.; MARTIN, P. Vers l'optique à ultra-haute intensité: l'exemple des miroirs plasmas. Reflets de la Physique, n. 19, p. 14-18, 2010.

RAMALHO, F.; FERRARO, N.; TOLEDO, P. Os fundamentos da Física 2. 9. ed. São Paulo: Moderna, 2007. p. 238-283.

RIBEIRO, J. A glass of wine a day does not keep optics away! Reflection and refraction images in wine glasses. The Physics Teacher, v. 51, n. 8, p. 506-507, 2013.

. Are you ready, kids? It's SpongeBob Triclops! The Physics Teacher, v. 53, n. 5, p. 298-299, 2015a.

Arquitetura óptica: análise de um modelo de associação de espelhos cilíndricos como representação dos prédios da Procuradoria Geral da República. Caderno Brasileiro de Ensino de Física, v. 32, n. 3, p. 837-855, 2015b.

. Construção geométrica e demonstração experimental da formação da "imagem ciclópica" em uma associação de dois espelhos planos. Revista Brasileira de Ensino de Fısica, v. 36, n. 4, p. 4401.1-4401.7, 2014.

RIBEIRO, J.; VERDEAUX, M. Atividades experimentais no ensino de óptica: uma revisão. Revista Brasileira de Ensino de Física, v. 34, n. 4, p. 4403.1-4403.9, 2012a.

.; Experimento simples, explicação nem tanto! Reflexão e polarização em óculos 3D. Física na Escola, v. 13, n. 1, p. 14-16, 2012 b.

RIVEROS, H.; ROSENBERGER, F. Images in the air. Physics Education, v. 47, n. 3, p. 342$345,2012$.

ROBINETT, R.; MULFINGER, C.; PASSANEAU, J. Optical realization of a circular billiard. The Physics Teacher, v. 36, n. 9, p. 547-552, 1998.

ROEDER, J. The effect of reflectors on light intensity The Physics Teacher v. 50, n. 4, p. 246, 2012.

ROJAS, R. Graphical synthesis of sign conventions in geometrical optics. European Journal of Physics, v. 34, n. 4, p. 1089-1093, 2013.

RÖMER, H. Theoretical optics, an introduction. 1. ed. Weinheim: Wiley-VCH, 2005. p. 114.

ROTHENSTEIN, B. The circular mirror moving at relativistic speeds. European Journal of Physics, v. 16, p. 124-126, 1995.

ROVŠEK, B. Making a cat's eye in a classroom. Physics Education, v. 45, n. 2, p. 186-189, 2010. 
RUSSELL, D. Alfresco reflections. The Physics Teacher, v. 48, n. 1, p. 74, 2010.

SALINAS, J.; SANDOVAL, J. Enseñanza Experimental de la Óptica Geométrica: Campos de Visión de Lentes y Espejos. Revista Brasileira de Ensino de Física, v. 22, n. 2, p. 259-265, 2000 .

SANTANA, A.; RODRIGUEZ, Y.; GOMEZ, E. Construction of ray diagrams in geometrical optics: a media-focused approach. Physics Education, v. 47, n. 6, p. 715-720, 2012.

ŞENGÖREN, S.; ÇOBAN, G. Some remarks on using the principal rays for teaching the elementary optics. Latin-American Journal of Physics Education, v. 5, n. 1, p. 123-125, 2011.

SHARMA, N. Reflection, refraction, and multislit interference. European Journal of Physics, v. 25, n. 1, p. 1-6, 2003.

SILVA, B. O modelo vibracional da luz de Huygens e o ensino de Física: Equívocos, desafios e possibilidades. Latin-American Journal of Physics Education, v. 5, n. 2, p. 467-474, 2011.

SILVA, M. Holografia: um projecto para o ensino secundário. Gazeta de Física, v. 34, n. 1, p. 51-54, 2011.

SILVA, M. Sistemas óticos com dois espelhos. Revista Brasileira de Ensino de Física, v. 34, n. 3, p. 3307.1-3307.8, 2012.

SILVA, O.; LABURÚ, C. Uma alternativa de baixo custo ao experimento de óptica denominado comercialmente "Magic Hologram-Mirage 3D". Caderno Brasileiro de Ensino de Física, v. 32, n. 1, p. 246-252, 2015.

SILVA, T. Banco óptico de baixo custo. Física na Escola, v. 5, n. 1, p. 15, 2004.

SILVEIRA, F.; AXT, R. O eclipse solar e as imagens produzidas no chão ou numa parede. Caderno Brasileiro de Ensino de Física, v. 24, n. 3, p. 353-359, 2007.

O que vemos quando projetamos a luz do Sol com um espelho plano: manchas luminosas ou imagens? Caderno Brasileiro de Ensino de Física, v. 24, n. 3, p. 353-359, 2001.

SILVEIRA, F.; AXT, R.; PIRES, M. O que vemos quando nos miramos em um espelho côncavo? Revista Brasileira de Ensino de Física, v. 26, n. 1, p. 19-25, 2004.

SMITH, A. From sight to light: the passage from ancient to modern optics. 1. ed. Chicago: University of Chicago Press, 2014.

SOUZA, L.; SILVA, L. HUGUENIN, J.; BALTHAZAR, W. Discutindo a natureza ondulatória da luz e o modelo da óptica geométrica através de uma atividade experimental de baixo custo. Revista Brasileira de Ensino de Física, v. 37, n. 4, p. 4311.1-4311.6, 2015. 
SUGON JR, Q.; MCNAMARA, D. A geometric algebra reformulation of geometric optics. American Journal of Physics, v. 72, n. 1, p. 92-97, 2004.

SZTRAJMAN, J.; RELA, A. Optical property of the ellipse derived from energy conservation. The Physics Teacher, v. 41, n. 4, p. 208-209, 2003.

TANTILlO, M. Paraffin Puzzler. The Physics Teacher, v. 46, n. 6, p. 380, 2008.

TAO, P; LEE, H. Classroom investigation of the Chinese "magic" mirror. The Physics Teacher, v. 35, n. 9, p. 536-538, 1997.

THOMPSON, G.; MATHIESON, D. The mirror box. The Physics Teacher, v. 39, n. 8, p. 508$509,2001$.

TIPLER, P.; MOSCA, G. Physics for scientists and engineers - with modern physics. 1. ed. New York: W. H. Freeman and Company, 2008. p. 1061.

TOEPKER, T. Purkinje images. The Physics Teacher v. 52, n. 3, p. 133, 2014.

UYSAL, A. Determining the thickness and refractive index of a mirror. The Physics Teacher, v. 48, n. 9, p. 602-603, 2010.

VAN BEVEREN, E.; KLEEFELD, F.; RUPP, G. Images in Christmas baubles. European Journal of Physics, v. 27, p. 337-346, 2006.

VAN METER, J. R.; CARLIP, S.; HARTEMANN, F. V. Reflection of plane waves from a uniformly accelerating mirror. American Journal of Physics, v. 69, n. 7, p. 783-787, 2001.

VANNONI, M.; MOLESINI, G.; BUAH-BASSUAH, P. One-step real-image reflection holograms. European Journal of Physics, v. 28, n. 2, p. 359-365, 2007.

VIEIRA, L. Measuring the dependence of reflectivity on the incidence angle: a technical note. European Journal of Physics, v. 35, n. 5, p. 55013-55019, 2014.

VOLLMER, M.; MÖLlMANN, K. Caustic effects due to sunlight reflections from skyscrapers: simulations and experiments. European Journal of Physics, v. 33, n. 5, p. 14291455, 2012.

VÖRÖS, Z; WEIHS, G. Foucault's method for measuring the speed of light with modern apparatus. European Journal of Physics, v. 36, n. 3, p. 13-26, 2015.

YURUMEZOGLU, K. Activity teaches mirror concepts. Physics Education, v. 44, n. 5, p. 462-464, 2009.

YURUMEZOGLU, K.; OGUZ-UNVER, A. Experiments on the nature of how multiple images form in a plane mirror. Latin-American Journal of Physics Education, v. 4, n. 3, p. 515-519, 2010. 
ZANARDI, D.; MURAMATSU, M. Um pouco de física na superfície do café. Física na Escola, v. 12, n. 1, p. 27-29, 2011. 